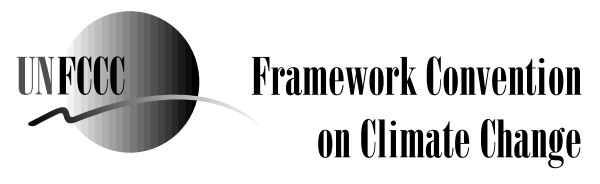

on Climate Change
Distr.

GENERAL

FCCC/CP/2001/13/Add.1

21 January 2002

Original: ENGLISH

CONFERENCE OF THE PARTIES

\title{
REPORT OF THE CONFERENCE OF THE PARTIES ON \\ ITS SEVENTH SESSION, HELD AT MARRAKESH \\ FROM 29 OCTOBER TO 10 NOVEMBER 2001
}

\section{Addendum}

\section{PART TWO: ACTION TAKEN BY THE CONFERENCE OF THE PARTIES}

Volume I

CONTENTS

I. THE MARRAKESH MINISTERIAL DECLARATION

Decision

1/CP.7. The Marrakesh Ministerial Declaration ...

II. THE MARRAKESH ACCORDS

Decision

2/CP.7. Capacity building in developing countries

(non-Annex I Parties).

3/CP.7. Capacity building in countries with economies in transition

4/CP.7. Development and transfer of technologies 
FCCC/CP/2001/13/Add.1

English

Page 2

$\underline{\text { Page }}$

5/CP.7. Implementation of Article 4, paragraphs 8 and 9, of the Convention (decision 3/CP.3 and Article 2, paragraph 3, and Article 3, paragraph 14, of the Kyoto Protocol)

6/CP.7. Additional guidance to an operating entity of the financial mechanism.

7/CP.7. Funding under the Convention

8/CP.7. Activities implemented jointly under the pilot phase (decisions 6/CP.4 and 13/CP.5)

9/CP.7. Matters relating to Article 3, paragraph 14, of the Kyoto Protocol

10/CP.7. Funding under the Kyoto Protocol

11/CP.7 Land use, land-use change and forestry

12/CP.7 Forest management activities under Article 3, paragraph 4, of the Kyoto Protocol:

the Russian Federation.

13/CP.7 "Good practices" in policies and measures among Parties included in Annex I to the Convention

14/CP.7. Impact of single projects on emissions in the commitment period 


\section{THE MARRAKESH MINISTERIAL DECLARATION}

Decision 1/CP. 7

\section{The Marrakesh Ministerial Declaration}

\section{The Ministers and other heads of delegation present at the seventh session of the Conference of the Parties to the United Nations Framework Convention on Climate Change,}

Mindful of the objective of the Convention, as set out in its Article 2,

Reaffirming that economic and social development and poverty eradication are the first and overriding priorities of the developing country Parties,

Believing that addressing the many challenges of climate change will make a contribution to achieving sustainable development,

Recognizing that the World Summit on Sustainable Development provides an important opportunity for addressing the linkages between climate change and sustainable development,

1. Note the decisions adopted by the seventh session of the Conference of the Parties in Marrakesh, constituting the Marrakesh Accords, that pave the way for the timely entry into force of the Kyoto Protocol;

2. Remain deeply concerned that all countries, particularly developing countries, including the least developed countries and small island States, face increased risk of negative impacts of climate change;

3. Recognize that, in this context, the problems of poverty, land degradation, access to water and food and human health remain at the centre of global attention; therefore, the synergies between the United Nations Framework Convention on Climate Change, the Convention on Biological Diversity, and the United Nations Convention to Combat Desertification in those Countries Experiencing Serious Drought and/or Desertification, Particularly in Africa, should continue to be explored through various channels, in order to achieve sustainable development;

4. Stress the importance of capacity-building, as well as of developing and disseminating innovative technologies in respect of key sectors of development, particularly energy, and of investment in this regard, including through private sector involvement, marketoriented approaches, as well as supportive public policies and international cooperation;

5. Emphasize that climate change and its adverse impacts have to be addressed through cooperation at all levels, and welcome the efforts of all Parties to implement the Convention; 
FCCC/CP/2001/13/Add.1

English

Page 4

6. Request the President of the Conference of the Parties at its seventh session and the Executive Secretary of the United Nations Framework Convention on Climate Change to continue to participate actively in the preparatory process for the World Summit, and in the Summit itself, and to report thereon to the Conference of the Parties at its eighth session.

$8^{\text {th }}$ plenary meeting

10 November 2001 


\section{THE MARRAKESH ACCORDS}

\section{Decision 2/CP.7}

\section{Capacity building in developing countries (non-Annex I Parties)}

\section{The Conference of the Parties,}

Being guided by Articles 4.1, 4.3, 4.4, 4.5 and 4.7, in the context of Article 3, and Articles 5 and 6 of the Convention,

Recalling the provisions related to capacity building for developing countries contained in its decisions 11/CP.1, 10/CP.2, 11/CP.2, 9/CP.3, 2/CP.4, 4/CP.4, 5/CP.4, 6/CP.4, 7/CP.4, 12/CP.4 and 14/CP.4,

Noting Article 10, paragraphs (c), (d) and (e), and Article 11 of the Kyoto Protocol,

Recalling also the paragraphs on capacity building of Agenda 21 and the Programme for the Further Implementation of Agenda 21,

Reaffirming its decision 10/CP.5,

Reaffirming also that capacity building for developing countries is essential to enable them to participate fully in, and to implement effectively their commitments under, the Convention,

Recalling further its decision 5/CP.6, containing the Bonn Agreements on the implementation of the Buenos Aires Plan of Action,

1. Adopts the framework for capacity building in developing countries annexed to this decision;

2. Decides that this framework should guide capacity-building activities related to the implementation of the Convention and effective participation in the Kyoto Protocol process;

3. Decides to give immediate effect to this framework in order to assist developing countries to implement the Convention and to effectively participate in the Kyoto Protocol process;

4. Notes that areas for capacity building identified under the Convention are relevant to the preparation of developing country Parties for their effective participation in the Kyoto Protocol process;

5. Requests the Global Environment Facility, as an operating entity of the financial mechanism, to report on its progress in support of the implementation of this framework in its reports to the Conference of the Parties; 
English

Page 6

6. Urges the operating entity of the financial mechanism to adopt a streamlined and expedited approach in financing activities within this framework;

7. Invites bilateral and multilateral agencies, and other intergovernmental organizations and institutions, to inform the Conference of the Parties, through the secretariat, of capacity-building activities conducted to assist developing country Parties with their implementation of the framework;

8. Encourages bilateral and multilateral agencies, and other intergovernmental organizations and institutions, to consult with developing countries in formulating programmes and action plans to support capacity-building activities in accordance with the annexed framework;

9. Requests the secretariat, in accordance with this framework for capacity building, and consistent with Article 8 of the Convention, to undertake the following tasks:

(a) To cooperate with the operating entity of the financial mechanism, its implementing agencies and other entities for capacity building, to facilitate the implementation of this framework;

(b) To collect, process, compile and disseminate, in both printed and electronic formats, the information needed by the Conference of the Parties or its subsidiary bodies to review the progress in the implementation of this framework for capacity building, drawing in particular on information contained in:

(i) National communications of developing country Parties relating to capacity-building activities;

(ii) National communications of Parties included in Annex II to the Convention on activities and programmes undertaken to facilitate capacity building in developing countries related to the implementation of this framework;

(iii) Reports from the Global Environment Facility and other agencies;

(c) To provide reports to the Conference of the Parties at each of its sessions on activities to implement this framework;

10. Decides that the Subsidiary Body for Implementation will regularly monitor the progress of the implementation of this framework, taking into account the information provided under paragraphs 9(b) and 9(c) above, and reporting to the Conference of the Parties at each of its sessions;

11. Decides to conduct a comprehensive review of the implementation of this framework at the ninth session of the Conference of the Parties, and every five years thereafter;

12. Invites Parties to provide information through national communications and other reports to enable the Subsidiary Body for Implementation to monitor progress in the implementation of this framework; 
FCCC/CP/2001/13/Add.1

English

Page 7

13. Recommends that the Conference of the Parties serving as the meeting of the Parties to the Kyoto Protocol, at its first session, adopt a decision containing a framework on capacity building that reaffirms the framework annexed to the present decision with additional reference to priority areas for capacity building relating to the implementation of the Kyoto Protocol.

$8^{\text {th }}$ plenary meeting

10 November 2001 
English

Page 8

\section{ANNEX \\ Framework for capacity building in developing countries}

\section{A. Purposes}

1. The present framework for capacity building in developing countries sets out the scope of, and provides the basis for action on, capacity building related to the implementation of the Convention and preparation for the effective participation of developing countries in the Kyoto Protocol process that will, in a coordinated manner, assist them in promoting sustainable development while meeting the objective of the Convention. It should serve as a guide for the Global Environment Facility as an operating entity of the financial mechanism, and be considered by multilateral and bilateral organizations in their capacity-building activities related to the implementation of the Convention and preparation for their effective participation in the Kyoto Protocol process.

\section{B. Guiding principles and approaches}

2. This framework for capacity-building in developing countries is guided and informed by, inter alia, Articles 4.1, 4.3, 4.4, 4.5 and 4.7, in the context of Article 3, and Articles 5, 6 and 11.1 of the Convention, and relevant provisions contained in decisions 11/CP.1, 10/CP.2, 11/CP.2, 9/CP.3, 2/CP.4, 4/CP.4, 5/CP.4, 6/CP.4, 7/CP.4, 12/CP.4, 14/CP.4, and 10/CP.5, ${ }^{1}$ and takes into account Article 10, paragraphs (c), (d), and (e), and Article 11 of the Kyoto Protocol.

3. Capacity-building activities related to the implementation of the Convention by developing countries and to the preparation for their effective participation in the Kyoto Protocol process should build on work already undertaken by developing countries, as well as on the work undertaken with support from multilateral and bilateral organizations.

4. The capacity-building needs already identified in the various decisions of the Conference of the Parties should continue to be comprehensively and promptly addressed to promote sustainable development in developing countries through the effective implementation of the Convention and preparation for their effective participation in the Kyoto Protocol process.

5. There is no "one size fits all" formula for capacity building. Capacity building must be country-driven, addressing the specific needs and conditions of developing countries and reflecting their national sustainable development strategies, priorities and initiatives. It is primarily to be undertaken by and in developing countries in accordance with the provisions of the Convention.

6. Capacity building is a continuous, progressive and iterative process, the implementation of which should be based on the priorities of developing countries.

\footnotetext{
1 For the full texts of decisions adopted by the Conference of the Parties at its first, second, third, fourth and fifth sessions, see documents FCCC/CP/1995/7/Add.1, FCCC/CP/1996/15/Add.1, FCCC/CP/1997/7/Add.1, FCCC/CP/1998/16/Add.1 and FCCC/CP/1999/6/Add.1, respectively.
} 
7. Capacity-building activities should be undertaken in an effective, efficient, integrated and programmatic manner, taking into consideration the specific national circumstances of developing countries.

8. Capacity-building activities undertaken within this framework should maximize synergies between the Convention and other global environmental agreements, as appropriate.

9. Capacity building is crucial to developing countries, especially those that are particularly vulnerable to the adverse effects of climate change. The special circumstances of least developed countries and small island developing States need to be taken into account in the implementation of this framework. They include:

(a) Fragile ecosystems;

(b) High population pressure and isolated geographic locations;

(c) Weak economies, low incomes, high levels of poverty and a lack of foreign investment;

(d) Land degradation, desertification;

(e) Undeveloped services, inter alia, meteorologic and hydrological services and water resources management;

(f) Lack of early warning systems for natural disaster management;

(g) Inadequate food security.

10. Capacity building involves "learning by doing". Demonstration projects may be used in identifying and learning about the specific capacities that need to be further developed in developing countries.

11. Existing national institutions have an important role to play in supporting capacitybuilding activities in developing countries. Such centres can incorporate traditional skills, knowledge and practices, to provide appropriate services in developing countries and facilitate information sharing. Whenever possible and effective, therefore, capacity building should mobilize these existing national, subregional and regional institutions and the private sector in developing countries, and build on existing processes and endogenous capacities.

12. National coordinating mechanisms and focal points and national coordinating entities have an important role to play in ensuring coordination at the country and regional levels and may serve as the focal point for coordinating capacity-building activities.

13. Multilateral and bilateral bodies are encouraged to take account of this framework in their consultations with developing countries when supporting capacity-building activities related to the implementation of the Convention and the preparation for the effective participation by developing countries in the Kyoto Protocol process. 


\section{Objective and scope of capacity building}

\section{Objective}

14. Capacity building should assist developing countries to build, develop, strengthen, enhance, and improve their capabilities to achieve the objective of the Convention through the implementation of the provisions of the Convention and the preparation for their effective participation in the Kyoto Protocol process.

\section{Scope}

15. The following is the initial scope of needs and areas for capacity building in developing countries as broadly identified in the annex to decision 10/CP.5, in the compilation and synthesis document prepared by the secretariat, ${ }^{2}$ and in submissions by Parties: ${ }^{3}$

(a) Institutional capacity building, including the strengthening or establishment, as appropriate, of national climate change secretariats or national focal points;

(b) Enhancement and/or creation of an enabling environment;

(c) National communications;

(d) National climate change programmes;

(e) Greenhouse gas inventories, emission database management, and systems for collecting, managing and utilizing activity data and emission factors;

(f) Vulnerability and adaptation assessment;

(g) Capacity building for implementation of adaptation measures;

(h) Assessment for implementation of mitigation options;

(i) Research and systematic observation, including meteorological, hydrological and climatological services;

(j) Development and transfer of technology;

(k) Improved decision-making, including assistance for participation in international negotiations;

(1) Clean development mechanism;

(m) Needs arising out of the implementation of Article 4, paragraphs 8 and 9, of the Convention;

(n) Education, training and public awareness;

2 FCCC/SB/2000/INF.1.

$3 \quad$ FCCC/SB/2000/INF.5. 
(o) Information and networking, including the establishment of databases.

16. Other capacity-building needs and possible responses are being identified by the Parties in their discussions of other issues. The decisions resulting from these discussions, as well as other activities related to the implementation of the Convention and preparation for the effective participation by developing countries in the Kyoto Protocol process, should continue to inform the scope and implementation of this framework.

\section{Specific scope for capacity building in least developed countries}

17. The least developed countries, and small island developing States amongst them, are among the most vulnerable to extreme weather events and the adverse effects of climate change. They also have the least capacity to cope with and adapt to the adverse effects of climate change. The following is the initial assessment of needs and priority areas for capacity building in these countries:

(a) Strengthening existing and, where needed, establishing national climate change secretariats or focal points to enable the effective implementation of the Convention and effective participation in the Kyoto Protocol process, including preparation of national communications;

(b) Developing an integrated implementation programme which takes into account the role of research and training in capacity building;

(c) Developing and enhancing technical capacities and skills to carry out and effectively integrate vulnerability and adaptation assessments into sustainable development programmes and develop national adaptation programmes of action;

(d) Strengthening existing and, where needed, establishing national research and training institutions in order to ensure the sustainability of the capacity-building programmes;

(e) Strengthening the capacity of meteorological and hydrological services to collect, analyse, interpret and disseminate weather and climate information to support implementation of national adaptation programmes of action;

(f) Enhancing public awareness (level of understanding and human capacity development).

\section{Implementation}

Actions to enhance the implementation of this framework, taking into account the initial scope outlined in paragraphs 15 to 17 above

18. All Parties should improve the coordination and effectiveness of capacity-building efforts through dialogue between and among Annex II Parties, developing country Parties, and bilateral and multilateral institutions. All Parties should support the operation of this framework and promote conditions conducive to the sustainability and effectiveness of capacity-building activities. 
English

Page 12

19. In implementing this framework, developing country Parties should:

(a) Continue to identify their specific needs, options and priorities for capacity building on a country-driven basis, taking into account existing capacities and past and current activities;

(b) Promote South-South cooperation by utilizing the services of institutions in developing countries that can support capacity-building activities at the national, subregional and regional levels, wherever possible and effective;

(c) Promote the participation of a wide range of stakeholders, including governments at all levels, national and international organizations, civil society and the private sector, as appropriate;

(d) Promote the coordination and sustainability of activities undertaken within this framework, including the efforts of national coordinating mechanisms, focal points, and national coordinating entities;

(e) Facilitate the dissemination and sharing of information on capacity-building activities conducted by developing countries for better coordination and South-South cooperation.

20. In implementing this framework, Annex II Parties should:

(a) Provide additional financial and technical resources to assist developing countries, in particular the least developed countries and small island developing States among them, in the implementation of this framework, including promptly available financial and technical resources to enable them to undertake country-level needs assessments and to develop specific capacitybuilding activities consistent with this framework;

(b) Respond to the capacity-building needs and priorities of developing countries, in particular the least developed countries and small island developing States among them, in a coordinated and timely manner, and support activities implemented at the national and, as appropriate, subregional and regional levels;

(c) Give particular attention to the needs of least developed countries and small island developing States among them.

\section{Financing and operation}

21. Financial and technical resources should be made available, through an operating entity of the financial mechanism and, as appropriate, through multilateral and bilateral agencies and the private sector, to assist developing countries, in particular the least developed countries and small island developing States among them, in the implementation of this framework.

22. In response to this framework, the operating entity of the financial mechanism should elaborate a country-driven strategy for its capacity-building activities. 
23. Multilateral and bilateral agencies are encouraged to take constructive action to support capacity-building activities in this framework through streamlined and coordinated approaches and in a timely manner.

24. Financial and other assistance is to be made available to developing countries, in particular to the least developed countries and small island developing States among them, to enable them to continue to determine, assess and prioritize their needs for capacity building in a simple, timely manner and to assist them in strengthening existing institutions and, when needed, to establish the institutional arrangements to implement effective capacity-building activities.

25. The capacity-building activities undertaken within this framework are to be countrydriven and implemented primarily at the country level.

26. In order to facilitate the exchange of information and cooperation, developing countries, in collaboration with relevant institutions, should identify regional, subregional and sectoral activities that can effectively and efficiently address common capacity-building needs.

27. The results of activities conducted by the Global Environment Facility as a multilateral financial institution, including the Capacity Development Initiative, as well as activities undertaken by multilateral, bilateral and private sector entities, may be considered in further developing capacity-building activities within this framework at the regional and subregional levels.

\section{Time frame}

28. This framework for capacity building should be implemented promptly, taking into account the immediate, medium- and long-term priority needs identified by developing countries.

29. Developing countries which have already identified their capacity-building priorities through ongoing work aimed at the implementation of the Convention should be able to promptly implement capacity-building activities under this framework.

30. The immediate priority needs of developing countries, in particular the least developed countries and small island developing States among them, should be addressed urgently in the implementation of this framework.

\section{Review of progress}

31. The Conference of the Parties, through the Subsidiary Body for Implementation, shall regularly monitor and review the progress in the implementation of this framework.

32. The Global Environment Facility, as an operating entity of the financial mechanism, is requested to report on its progress in support of the implementation of this framework in its reports to the Conference of the Parties. 
FCCC/CP/2001/13/Add.1

English

Page 14

Role of the secretariat

33. In accordance with this framework for capacity building, the secretariat is requested, consistent with Article 8 of the Convention, to undertake the following tasks:

(a) To cooperate with the operating entity of the financial mechanism, its implementing agencies and other entities for capacity building to facilitate the implementation of this framework;

(b) To collect, process, compile and disseminate the information needed by the Conference of the Parties or its subsidiary bodies to review the progress made in the implementation of this framework for capacity building. 


\section{Decision 3/CP.7}

\section{Capacity building in countries with economies in transition}

\section{The Conference of the Parties,}

Recalling its decision 11/CP.5,

Recalling Articles 4.1, 4.2, 4.5 and 4.6, 5, 6 and 12 of the Convention,

Noting Articles 2, 3, 5, 6, 7, 10 and 17 of the Kyoto Protocol,

Further recalling its decisions 9/CP.2, 6/CP.4 and 7/CP.4,

Having considered the relevant recommendations of the Subsidiary Body for Scientific and Technological Advice and the Subsidiary Body for Implementation, ${ }^{1}$

Recalling further its decision 5/CP.6, containing the Bonn Agreements on the implementation of the Buenos Aires Plan of Action,

1. Adopts the framework for capacity-building activities in countries with economies in transition contained in the annex below;

2. Decides to give immediate effect to this framework, in order to assist Parties with economies in transition to implement the Convention;

3. Notes that many areas for capacity building identified under the Convention are also relevant to the preparation of Parties with economies in transition for participation in the Kyoto Protocol when it enters into force;

4. Decides to review the effectiveness of the implementation of the framework at regular intervals;

5. Invites Parties included in Annex II to the Convention (Annex II Parties) and Parties with economies in transition to provide information to enable the Conference of the Parties and the subsidiary bodies to monitor progress in the implementation of this framework, consistent with guidelines for the preparation of national communications;

6. Urges Annex II Parties, through multilateral agencies, including through the Global Environment Facility within its mandate, and bilateral agencies and the private sector, as appropriate, to make available financial and technical support for the implementation of this framework for capacity building, including assistance for the development of national action plans of Parties with economies in transition consistent with their priorities;

7. Further urges multilateral and bilateral agencies to coordinate their activities in support of the implementation of this framework for capacity building;

1 FCCC/SBSTA/2000/10 and FCCC/SBI/2000/10. 
FCCC/CP/2001/13/Add.1

English

Page 16

8. Recommends that the Conference of the Parties serving as the meeting of the Parties to the Kyoto Protocol, at its first session, adopt a decision endorsing a framework for capacity building under the Convention that parallels the framework contained in the annex below, with additional reference to priority areas for capacity building relating to implementation of the Kyoto Protocol;

9. Requests the secretariat, consistent with Article 8 of the Convention:

(a) To cooperate with multilateral and bilateral institutions to facilitate the implementation of this framework;

(b) To collect, process, compile and disseminate the information needed by the Conference of the Parties and the subsidiary bodies to monitor progress in the implementation of this framework. 


\title{
ANNEX \\ Framework for capacity building in countries with economies in transition
}

\begin{abstract}
A. Purpose
1. The purpose of this framework for capacity building is to set out the scope and basis for action for capacity-building activities in countries with economies in transition (EIT Parties) under the Convention and for the preparation of EIT Parties for their participation in the Kyoto Protocol when it enters into force.
\end{abstract}

\section{B. Guiding principles and approaches}

2. This framework for capacity-building in EIT Parties is guided and informed by, inter alia, Articles 4.1, 4.2, 4.5 and 4.6, 5, 6 and 12 of the Convention and relevant provisions contained in decisions 9/CP.2, 6/CP.4, 7/CP.4 and 11/CP.5, ${ }^{2}$ and takes account of Articles 2, 3, 5, 6, 7 and 17 of the Kyoto Protocol.

3. As Parties included in Annex I, EIT Parties have quantified emission limitation and reduction commitments that impose challenges to their existing capacities to implement the Convention. As Parties undergoing the process of transition to a market economy, they need to enhance their ability to address climate change issues. Capacity building is therefore critical to the effective implementation by EIT Parties of their commitments under the Convention and the preparation of EIT Parties for their participation in the Kyoto Protocol when it enters into force.

4. Capacity building for EIT Parties must be country-driven, be consistent with their national sustainable development strategies, reflect their national initiatives and priorities, respond to needs determined and prioritized by EIT Parties themselves, and be primarily undertaken by and in EIT Parties in partnership with other Parties and relevant organizations, as appropriate, in accordance with the provisions of the Convention.

5. Capacity building should contribute to the effective implementation of the Convention by EIT Parties and the preparation of EIT Parties for their participation in the Kyoto Protocol when it enters into force.

6. Capacity-building efforts are more effective when they take place within an enabling environment conducive to the development of human, institutional and technical capacity.

7. Capacity building should be results-oriented and implemented in an integrated and programmatic manner to facilitate its monitoring and evaluation, cost-effectiveness and efficiency.

8. Capacity building is a continuous process aimed at strengthening or establishing, as appropriate, relevant institutions, organizational structures, and human resources in order to strengthen expertise relevant to paragraph 3 of this framework.

\footnotetext{
2 For the full texts of decisions adopted by the Conference of the Parties at its second, fourth and fifth sessions, see FCCC/CP/1996/15/Add.1, FCCC/CP/1998/16/Add.1 and FCCC/CP/1999/6/Add.1 respectively.
} 
English

Page 18

9. Capacities should be developed and strengthened in a manner and under conditions that will work towards sustainability and support the short- and long-term objectives and priorities of EIT Parties under the Convention.

10. Capacity building involves "learning by doing". Capacity-building activities should be designed and implemented in a flexible manner.

11. Capacity building should improve the coordination and effectiveness of existing efforts and promote the participation of, and dialogue between, a wide range of actors and constituencies, including governments at all levels, international organizations, civil society and the private sector.

12. Wherever possible, capacity-building should utilize existing institutions and bodies and build on existing processes and endogenous capacities.

13. National focal points and other institutions, such as research centres and universities and other relevant organizations, should play an important role in providing capacity-building services and facilitating the flow of knowledge, best practices and information.

14. Capacity-building should be designed so that it results in the development, strengthening and enhancement of institutional capacities, human resources, knowledge and information, methodologies and practices, and the participation and networking of EIT Parties to promote sustainable development, and for the purpose set out in paragraph 1 of this framework.

15. Capacity building in support of achieving the objectives of the Convention should maximize synergies between the Convention and other global environmental agreements, as appropriate.

16. Capacity building is more effective when it is coordinated at all levels (national, regional and international) through dialogue between and among Annex I Parties, and when past and existing efforts are taken into account.

\section{Objective and scope of capacity building}

\section{Objective}

17. To build the capacity of EIT Parties to enable them to effectively implement the objective of the Convention and to prepare for their participation in the Kyoto Protocol when it enters into force.

\section{Scope}

18. To ensure that capacity-building efforts are country-driven, each EIT Party should, within the scope of capacity building, determine its specific objectives, needs, priorities, and options to implement the Convention and to prepare for its participation in the Kyoto Protocol when it enters into force, consistent with its national sustainable development strategy, taking into account existing capacities and past and current activities undertaken by the country itself, and in partnership with bilateral and multilateral institutions and the private sector. 
19. The needs for capacity building in EIT Parties were first identified in the compilation and synthesis document prepared by the secretariat ${ }^{3}$ based on the submissions of EIT Parties. ${ }^{4}$ The general areas and needs for capacity building are listed below. This scope for capacity-building may be revised as further information is made available and as needs and priorities are further identified.

20. General priority areas for capacity-building identified by EIT Parties related to the implementation of the Convention, which may also be relevant to their preparation for participation in the Kyoto Protocol, are to be identified in their national action plan for capacity building, and include:

(a) National greenhouse gas (GHG) inventories;

(b) Projections of GHG emissions;

(c) Policies and measures, and the estimation of their effects;

(d) Impact assessment and adaptation;

(e) Research and systematic observation;

(f) Education, training and public awareness;

(g) Transfer of environmentally sound technologies;

(h) National communications and national climate action plans;

(i) National systems for estimation of GHG emissions;

(j) Modalities for accounting relating to targets, timetables and national registries;

(k) Reporting obligations;

(1) Joint implementation projects and emissions trading.

21. In order to maximize available resources for capacity building and to facilitate exchange and cooperation among EIT Parties, multilateral and bilateral agencies in consultation with EIT Parties should assist, as appropriate, the efforts of EIT Parties themselves to identify, develop and implement national, regional, subregional and sectoral activities that meet the capacity-building needs of EIT Parties. The results of the current and next phase of the Capacity Development Initiative of the Global Environment Facility (GEF) could provide valuable inputs for these activities.

\footnotetext{
3 FCCC/SB/2000/INF.2.

$4 \quad$ FCCC/SB/2000/INF.7.
} 
English

Page 20

\section{Implementation}

\section{Responsibilities for implementation}

22. In implementing the activities undertaken within this framework for capacity-building, EIT and Annex II Parties have the following mutual responsibilities:

(a) To improve the coordination and effectiveness of existing efforts;

(b) To provide information to enable the Conference of the Parties to monitor progress in the implementation of this framework for capacity building.

23. In the implementation of this framework for capacity building, EIT Parties have the following responsibilities:

(a) To provide an enabling environment to promote the sustainability and effectiveness of capacity-building activities relating to the implementation of the ultimate objective of the Convention;

(b) To identify their specific needs, priorities and options for capacity building on a country-driven basis, taking into account existing capacities and past and current activities;

(c) To identify and provide information on their own capacity-building activities;

(d) To promote cooperation among EIT Parties as well as to report to the Conference of the Parties on these activities in their national communications;

(e) To ensure the mobilization and sustainability of national capacities, including the institutional leadership necessary for national coordination and the effectiveness of capacitybuilding activities;

(f) To promote the participation in and access to capacity-building activities of all stakeholders, including governments, civil society and the private sector, as appropriate.

24. In cooperating with EIT Parties to support the implementation of this framework for capacity building, Annex II Parties have the following responsibilities:

(a) To assist EIT Parties, including by making available financial and other resources, to undertake country-level needs assessments to enable them to effectively implement the Convention and, as appropriate, to prepare them for participation in the Kyoto Protocol when it enters into force;

(b) To assist EIT Parties, including through the provision of financial and other resources, to implement options for capacity building consistent with their specific priorities and this framework.

\section{Financing}

25. The Annex II Parties, through multilateral agencies, including through the Global Environment Facility within its mandate, and bilateral agencies and the private sector as 
appropriate, are requested to make available financial and technical support to assist EIT Parties in the implementation of this framework for capacity building.

\section{Time frame}

26. The implementation of activities undertaken within this framework for capacity building should commence as soon as possible.

\section{Monitoring of progress}

27. The Conference of the Parties, through the subsidiary bodies, shall monitor the effectiveness of the implementation of this framework for capacity building.

28. Information to enable the Conference of the Parties to monitor the effectiveness of the implementation of this framework should be reported by Parties. Other institutions involved in capacity building in EIT Parties are invited to provide information for this purpose.

\section{Role of the secretariat}

29. In accordance with this framework for capacity building, the secretariat is requested, consistent with Article 8 of the Convention, to undertake the following tasks:

(a) To cooperate with multilateral and bilateral institutions to facilitate the implementation of this framework;

(b) To collect, process, compile and disseminate the information needed by the Conference of the Parties or its subsidiary bodies to monitor progress in the implementation of this framework for capacity building. 


\title{
Decision 4/CP.7
}

\section{Development and transfer of technologies (decisions 4/CP.4 and 9/CP.5)}

\author{
The Conference of the Parties,
}

Recalling chapter 34 of Agenda 21 and the relevant provisions of the programme for the further implementation of Agenda 21 on the transfer of environmentally sound technologies adopted by the United Nations General Assembly at its nineteenth special session, ${ }^{1}$

Pursuant to the relevant provisions of the Convention, in particular, its Articles 4.1, 4.3, 4.5, 4.7, 4.8 and 4.9, Article 9.2(c), Articles 11.1, 11.5, and Articles 12.3 and 12.4,

Recalling its decisions 11/CP.1, 13/CP.1, 7/CP.2, 9/CP.3, 4/CP.4, 9/CP.5 and the relevant provisions of its decision 1/CP.4 on the Buenos Aires Plan of Action,

Recalling further its decision 5/CP.6, containing the Bonn Agreements on the implementation of the Buenos Aires Plan of Action,

1. Decides to adopt the framework for meaningful and effective actions to enhance the implementation of Article 4, paragraph 5, of the Convention contained in the annex to this decision as part of the outcome of the technology transfer consultative process (decision 4/CP.4) and the Buenos Aires Plan of Action (decision 1/CP.4);

2. Decides to establish an expert group on technology transfer to be nominated by Parties, with the objective of enhancing the implementation of Article 4, paragraph 5, of the Convention, including, inter alia, by analysing and identifying ways to facilitate and advance technology transfer activities and making recommendations to the Subsidiary Body for Scientific and Technological Advice. The Conference of the Parties will review at its twelfth session the progress of the work and terms of reference, including, if appropriate, the status and continuation of the expert group;

3. Requests the Global Environment Facility, as an operating entity of the financial mechanism of the Convention, to provide financial support for the implementation of the annexed framework through its climate change focal area and the special climate change fund established under decision 7/CP.7;

4. Urges developed country Parties to provide technical and financial assistance, as appropriate, through existing bilateral and multilateral cooperative programmes to support the efforts of the Parties in implementing the programmes and measures identified in the annexed framework and to enhance the implementation of Article 4, paragraph 5, of the Convention;

\footnotetext{
A/RES/S-19/2.
} 
FCCC/CP/2001/13/Add.1

English

Page 23

5. Requests the Convention secretariat:

(a) To consult with relevant international organizations, and solicit information on their capabilities and abilities to support certain activities identified in the framework for meaningful and effective actions contained in the annex to this decision, and to report on its findings to the Subsidiary Body for Scientific and Technological Advice at its seventeenth session;

(b) To facilitate the implementation of the annexed framework in cooperation with the Parties, the Global Environment Facility and other relevant international organizations.

$8^{\text {th }}$ plenary meeting 10 November 2001 


\section{ANNEX}

\section{Framework for meaningful and effective actions to enhance the implementation of Article 4, paragraph 5, of the Convention}

\section{A. Purpose}

1. The purpose of this framework is to develop meaningful and effective actions to enhance the implementation of Article 4, paragraph 5, of the Convention by increasing and improving the transfer of and access to environmentally sound technologies (ESTs) and know-how.

\section{B. Overall approach}

2. The successful development and transfer of ESTs and know-how requires a countrydriven, integrated approach, at a national and sectoral level. This should involve cooperation among various stakeholders (the private sector, governments, the donor community, bilateral and multilateral institutions, non-governmental organizations and academic and research institutions), including activities on technology needs assessments, technology information, enabling environments, capacity building and mechanisms for technology transfer.

\section{Key themes and areas for meaningful and effective actions}

1. Technology needs and needs assessments

\section{Definition}

3. Technology needs and needs assessments are a set of country-driven activities that identify and determine the mitigation and adaptation technology priorities of Parties other than developed country Parties, and other developed Parties not included in Annex II, particularly developing country Parties. They involve different stakeholders in a consultative process to identify the barriers to technology transfer and measures to address these barriers through sectoral analyses. These activities may address soft and hard technologies, such as mitigation and adaptation technologies, identify regulatory options and develop fiscal and financial incentives and capacity building.

\section{Purpose}

4. The purpose of technology needs assessments is to assist in identifying and analysing priority technology needs, which can form the basis for a portfolio of EST projects and programmes which can facilitate the transfer of, and access to, the ESTs and know-how in the implementation of Article 4, paragraph 5, of the Convention.

\section{Implementation}

5. Parties other than developed country Parties, and other developed Parties not included in Annex II, particularly developing country Parties, are encouraged to undertake assessments of country-specific technology needs, subject to the provision of resources, as appropriate to country-specific circumstances, from developed country Parties and other developed Parties included in Annex II. Other organizations in a position to do so may also assist in facilitating the 
technology needs assessment process. Parties are encouraged to make available information on the results of their needs assessments in their national communications, other related national reports and channels (for example, technology information clearing houses) for consideration by the Subsidiary Body for Scientific and Technological Advice (SBSTA) on a regular basis.

6. Developed country Parties and other developed Parties included in Annex II to the Convention are urged to facilitate and support the needs assessments process, recognizing the special circumstances of least developed countries.

7. The Chairman of the SBSTA, with the assistance of the secretariat, in consultation with the expert group on technology transfer, is requested to organize a meeting with representatives from governments, experts drawn from the UNFCCC roster of experts, and representatives from relevant international organizations, to identify methodologies needed to undertake technology needs assessments and to report its findings to the SBSTA at its sixteenth session.

\section{Technology information}

\section{Definition}

8. The technology information component of the framework defines the means, including hardware, software and networking, to facilitate the flow of information between the different stakeholders to enhance the development and transfer of environmentally sound technologies. This technology information component of the framework could provide information on technical parameters, economic and environmental aspects of environmentally sound technologies and the identified technology needs of Parties not included in Annex II, particularly developing country Parties, as well as information on the availability of environmentally sound technologies from developed countries and opportunities for technology transfer.

\section{Purpose}

9. The technology information component serves to establish an efficient information system in support of technology transfer and to improve the generation and flow of, access to, and quality of technical, economic, environmental and regulatory information relating to the development and transfer of ESTs under the Convention.

\section{Implementation}

10. The Convention secretariat is requested:

(a) To build on the success of the current work, including that undertaken by the secretariat, in cooperation with the Climate Technology Initiative and other relevant organizations, inter alia, to develop a new search engine on the Internet that will allow for quick access to existing inventories of environmentally sound and economically viable technologies and know-how, including those conducive to mitigating and adapting to climate change;

(b) To identify, in collaboration with regional centres and other institutions, gaps in existing EST inventories, and update and develop inventories, as needed; 
English

Page 26

(c) To organize an expert workshop on technology information, including options for the establishment of an information clearing house and enhancement of information centres and networks, and to further define user needs, criteria for quality control, technical specifications and the role and contribution of the Parties;

(d) To accelerate its work on the development of a technology transfer information clearing house by coordinating with Parties and relevant United Nations agencies and other international organizations and institutions, and developing options for implementation, in particular, networking of an international technology information clearing house under the Convention, and enhancement of technology information centres and networks. A report on the options and recommendations should be provided to the SBSTA at its sixteenth session.

11. An information clearing house, including a network of technology information centres, should be established under the auspices of the secretariat, by the time of the eighth session of the Conference of the Parties, taking into consideration the conclusions of the SBSTA, at its sixteenth session, on the above-mentioned report.

\section{Enabling environments}

\section{Definition}

12. The enabling environments component of the framework focuses on government actions, such as fair trade policies, removal of technical, legal and administrative barriers to technology transfer, sound economic policy, regulatory frameworks and transparency, all of which create an environment conducive to private and public sector technology transfer.

\section{Purpose}

13. The purpose of the enabling environments component of the framework is to improve the effectiveness of the transfer of environmentally sound technologies by identifying and analysing ways of facilitating the transfer of environmentally sound technologies, including the identification and removal of barriers at each stage of the process.

\section{Implementation}

14. The following are means of creating enabling environments for technology transfer:

(a) All Parties, particularly developed country Parties, are urged to improve, as appropriate, the enabling environment for the transfer of environmentally sound technologies through the identification and removal of barriers, including, inter alia, strengthening environmental regulatory frameworks, enhancing legal systems, ensuring fair trade policies, utilizing tax preferences, protecting intellectual property rights and improving access to publicly funded technologies and other programmes, in order to expand commercial and public technology transfer to developing countries;

(b) All Parties are urged to explore, as appropriate, opportunities for providing positive incentives, such as preferential government procurement and transparent and efficient approval procedures for technology transfer projects, which support the development and diffusion of environmentally sound technologies; 
(c) All Parties are urged to promote joint research and development programmes, as appropriate, both bilaterally and multilaterally;

(d) Developed country Parties are encouraged to promote further and to implement facilitative measures, for example export credit programmes and tax preferences, and regulations, as appropriate, to promote the transfer of environmentally sound technologies;

(e) All Parties, particularly developed country Parties, are encouraged to integrate, as appropriate, the objective of technology transfer to developing countries into their national policies, including environmental and research and development policies and programmes;

(f) Developed countries are encouraged to promote, as appropriate, the transfer of publicly owned technologies.

\section{Capacity building}

\section{Definition}

15. Within the context of enhancing the implementation of Article 4, paragraph 5, of the Convention, capacity building is a process which seeks to build, develop, strengthen, enhance and improve existing scientific and technical skills, capabilities and institutions in Parties other than developed country Parties, and other developed Parties not included in Annex II, particularly developing country Parties, to enable them to assess, adapt, manage and develop environmentally sound technologies.

16. Capacity building must be country-driven, addressing specific needs and conditions of developing countries and reflecting their national sustainable development strategies, priorities and initiatives. It is primarily to be undertaken by and in developing countries in accordance with the provisions of the Convention.

\section{Purpose}

17. The purpose of capacity building under this framework is to strengthen the capacities of Parties other than developed country Parties and other developed Parties not included in Annex II, particularly developing country Parties, to promote the widespread dissemination, application and development of environmentally sound technologies and know-how, to enable them to implement the provisions of the Convention. Capacity building under this framework should be guided by the principles established in the decisions related to capacity building (decisions 2/CP.7 and 3/CP.7).

\section{Scope}

18. The following sets out the initial scope of the needs and areas for capacity building of Parties, other than developed country Parties and other developed Parties not included in Annex II, particularly developing country Parties, for the transfer of, and access to, environmentally sound technologies and know-how:

(a) Implementation of regional, subregional and/or national capacity-building activities related to the transfer and development of technologies; 
English

Page 28

(b) Enhancement of the awareness of financial institutions, public, private and international, of the need to evaluate environmentally sound technologies on an equal footing with other technology options;

(c) Provision of opportunities for training in the use of environmentally sound technologies through demonstration projects;

(d) Enhancement of skills in the adoption, adaptation, installation, operation and maintenance of specific environmentally sound technologies and a broadening of understanding of methodologies for evaluating alternative technological options;

(e) Strengthening of the capacities of existing national and regional institutions relevant to technology transfer, taking into account country- and sector-specific circumstances, including South-South cooperation and collaboration;

(f) Training in project development and the management and operation of climate technologies;

(g) Development and implementation of standards and regulations promoting the use, transfer of, and access to ESTs, taking cognizance of country-specific policies, programmes and circumstances;

(h) Development of skills and know-how in conducting technology needs assessments;

(i) Improvement of knowledge on energy efficiency and the utilization of renewable energy technologies.

19. The following sets out the initial scope of the needs and areas for capacity building for the development and enhancement of endogenous capacities and technologies in developing countries. These shall be country-driven processes supported by developed country Parties:

(a) To establish and/or strengthen, as appropriate, relevant organizations and institutions in developing countries;

(b) To establish and/or strengthen, to the extent possible, training, expert exchange, scholarship and cooperative research programmes in relevant national and regional institutions in developing countries for the transfer, operation, maintenance, adaptation, diffusion and development of environmentally sound technologies;

(c) To build capacity for adapting to the adverse effects of climate change;

(d) To strengthen the endogenous capacities and capabilities in research, development, technological innovation, adoption and adaptation, and technology for systematic observation relevant to climate change and its associated adverse effects;

(e) To improve knowledge in the areas of energy efficiency and the utilization of renewable energy technologies. 


\section{Implementation}

20. Developed country Parties and other Parties included in Annex II shall take all practicable steps:

(a) To make available resources to assist developing countries in the implementation of capacity building to enhance the implementation of Article 4, paragraph 5, taking into account the provisions of paragraphs 18 and 19 above. These resources should include adequate financial and technical resources to enable developing countries to undertake country-level needs assessments and to develop specific capacity-building activities consistent with enhancing the implementation of Article 4, paragraph 5;

(b) To respond to the capacity-building needs and priorities of developing countries in a coordinated and timely manner, and support activities implemented at the national and, as appropriate, subregional and regional levels;

(c) To give particular attention to the needs of least developed countries and small island developing States.

21. All Parties should improve the coordination and effectiveness of capacity-building activities relating to the development and transfer of technologies. All Parties should promote conditions conducive to the sustainability and effectiveness of these capacity-building activities.

\section{Mechanisms for technology transfer}

\section{Definition}

22. The mechanisms for technology transfer, as identified in this section, are to facilitate the support of financial, institutional and methodological activities: (a) to enhance the coordination of the full range of stakeholders in different countries and regions; (b) to engage them in cooperative efforts to accelerate the development and diffusion, including transfer, of environmentally sound technologies, know-how and practices to and between Parties other than developed country Parties and other developed Parties not included in Annex II, particularly developing country Parties, through technology cooperation and partnerships (public/public, private/public and private/private); and (c) to facilitate the development of projects and programmes to support such ends.

\section{Purpose}

23. The purpose of the proposed mechanisms is to develop meaningful and effective actions to enhance the implementation of Article 4, paragraph 5, of the Convention by increasing the transfer of and access to environmentally sound technologies and know-how.

\section{Implementation - Institutional arrangement for technology transfer}

24. Functions: To provide scientific and technical advice on the advancement of the development and transfer of environmentally sound technologies and know-how under the Convention, including the preparation of an action plan to enhance the implementation of Article 4, paragraph 5, of the Convention. 
FCCC/CP/2001/13/Add.1

English

Page 30

25. The terms of reference of the expert group on technology transfer appear in the appendix below.

26. The expert group on technology transfer shall comprise 20 experts, as follows:

(a) Three members from each of the regions of the Parties not included in Annex I, namely Africa, Asia and the Pacific, and Latin America and the Caribbean;

(b) One member from the small island developing States;

(c) Seven members from Parties included in Annex I; and

(d) Three members from relevant international organizations.

27. The secretariat shall facilitate the organization of meetings of the group and the preparation of its reports to the SBSTA at its subsequent sessions and to the Conference of the Parties.

28. The expert group on technology transfer shall meet twice a year in conjunction with the sessions of the subsidiary bodies. 
FCCC/CP/2001/13/Add.1

English

Page 31

\section{APPENDIX}

\section{Terms of reference of the expert group on technology transfer}

1. The expert group on technology transfer shall have the objectives of enhancing the implementation of Article 4, paragraph 5, of the Convention and advancing the technology transfer activities under the Convention.

2. The expert group on technology transfer shall analyse and identify ways to facilitate and advance technology transfer activities, including those identified in the annex to decision 3/CP.7, and make recommendations to the Subsidiary Body for Scientific and Technological Advice (SBSTA).

3. The expert group on technology transfer shall report on its work each year and propose a programme of work for the following year for decision by the SBSTA.

4. The members of the expert group on technology transfer shall be nominated by Parties for a period of two years and be eligible to serve two consecutive terms. The SBSTA shall ensure that half of the members of the expert group nominated initially shall serve for a period of three years, taking into account the need to maintain the overall balance of the group. Every year thereafter, half of the members shall be nominated for a period of two years. Appointment pursuant to paragraph 5 shall count as one term. The members shall remain in office until their successors are nominated. The members from three relevant international organizations shall serve on an issue-oriented basis.

5. If a member of the expert group on technology transfer resigns or is otherwise unable to complete the assigned term of office or to perform the functions of that office, the expert group may decide, bearing in mind the proximity of the next session of the Conference of the Parties, to request the group that had nominated the member to nominate another member to replace the said member for the remainder of that member's mandate. In such a case, the expert group shall take into account any views expressed by the group that had nominated the member.

6. The expert group on technology transfer shall annually elect a chairperson and a vice-chairperson from among its members, with one being a member from a Party included in Annex I and the other being a member from a Party not included in Annex I. The positions of chairperson and vice-chairperson shall alternate annually between a member from a Party included in Annex I and a member from a Party not included in Annex I.

7. The members of the expert group on technology transfer shall serve in their personal capacity and shall have expertise in any of the following areas, inter alia, greenhouse gas mitigation and adaptation technologies, technology assessments, information technology, resource economics, or social development. 


\section{Decision 5/CP.7}

\section{Implementation of Article 4, paragraphs 8 and 9, of the Convention (decision 3/CP.3 and Article 2, paragraph 3, and Article 3, paragraph 14, of the Kyoto Protocol) ${ }^{1}$}

\section{The Conference of the Parties,}

Determined to protect the climate system for present and future generations,

Recalling its decisions 11/CP.1, 3/CP.3, 1/CP.4, 5/CP.4 and 12/CP.5,

Recalling further its decision 5/CP.6, containing the Bonn Agreements on the implementation of the Buenos Aires Plan of Action,

Recognizing the specific needs and concerns of developing country Parties referred to in Article 4, paragraph 8, of the Convention, and the specific needs and special situations of the least developed countries referred to in Article 4, paragraph 9,

Recognizing that low-lying and other small island countries, countries with low-lying coastal, arid and semi-arid areas or areas liable to floods, drought and desertification, and developing countries with fragile mountainous ecosystems are particularly vulnerable to the adverse effects of climate change,

Recognizing the special difficulties of those countries, especially developing countries, whose economies are particularly dependent on fossil fuel production, use and exportation, as a consequence of action taken to limit greenhouse gas emissions,

Reaffirming that Parties should protect the climate system for the benefit of present and future generations of humankind, on the basis of equity and in accordance with their common but differentiated responsibilities and respective capabilities, and that, accordingly, the developed country Parties should take the lead in combating climate change and the adverse effects thereof,

Reaffirming that the specific needs and special circumstances of developing country Parties, especially those that are particularly vulnerable to the adverse effects of climate change, and of those Parties, especially developing country Parties, which would have to bear a disproportionate or abnormal burden under the Convention, should be given full consideration,

Affirming that responses to climate change should be coordinated with social and economic development in an integrated manner with a view to avoiding adverse impacts on the latter, taking into full account the legitimate priority needs of developing countries for the achievement of sustained economic growth and the eradication of poverty,

\footnotetext{
1 Paragraphs 13, 17, and 18 of the draft decision contained in document FCCC/CP/2001/5/Add.1 have been omitted from the final text of this decision, since their content is subsumed in decisions 6/CP.7, 28/CP.7 and 29/CP.7 and by the conclusions contained in section V.D. of document FCCC/CP/2001/13/Add.4.
} 
Acknowledging the efforts already made by Parties to meet the specific needs and concerns of developing country Parties, in particular the least developed countries, with regard to adaptation,

Acknowledging the need to sensitize policy makers and the general public in Parties not included in Annex I to the Convention to climate change and its effects, in accordance with Article 6(a) of the Convention,

Having considered the report, ${ }^{2}$ in two parts, on the two workshops referred to in decision 12/CP.5,

Noting the many persistent uncertainties highlighted by those workshops, particularly with regard to the impact of response measures,

Insisting that the extent to which developing country Parties will effectively implement their commitments will depend on the effective implementation by the developed country Parties of their commitments relating to financial resources and transfer of technology and will also take fully into account that economic and social development and poverty eradication are the first and overriding priorities of the developing country Parties,

Acknowledging that the impact of the implementation of response measures will differ significantly from country to country, depending on each country's unique national circumstances, including the structure of its economy, trade and investment, natural resource endowment, social system, legal regime and population growth rate,

Recognizing that the least developed country Parties are among the most vulnerable to the adverse effects of climate change, and in particular that widespread poverty limits their adaptive capacity,

Acknowledging that the human, infrastructural and economic conditions of the least developed countries severely limit their capacities to participate effectively in the climate change process,

Noting that many of the least developed country Parties do not have the capacity to prepare and submit national communications in the foreseeable future,

\section{ADVERSE EFFECTS OF CLIMATE CHANGE}

1. Asserts the importance of a country-driven approach that allows developing country Parties to pursue the specific activities most appropriate to their unique national circumstances;

2. Insists that action related to adaptation follow an assessment and evaluation process, based on national communications and/or other relevant information, so as to prevent maladaptation and to ensure that adaptation actions are environmentally sound and will produce real benefits in support of sustainable development;

\footnotetext{
$2 \mathrm{FCCC} / \mathrm{SB} / 2000 / 2$.
} 
English

Page 34

3. Encourages Parties not included in Annex I to the Convention (non-Annex I Parties) to provide information, including in their national communications, and/or any other relevant information sources, on their specific needs and concerns arising from the adverse effects of climate change;

4. Stresses the need for Parties included in Annex II to the Convention (Annex II Parties) to provide detailed information, including in their national communications, on support programmes to meet the specific needs and circumstances of developing country Parties arising from the adverse effects of climate change;

5. Encourages Parties to exchange information on their experience regarding the adverse effects of climate change and on measures to meet their needs arising from these adverse effects;

6. Underlines the importance of the ongoing work of the secretariat in compiling and disseminating information on methods and tools for evaluating impacts and adaptation strategies;

7. Decides that the implementation of the following activities shall be supported through the Global Environment Facility (in accordance with decision 6/CP.7) and other bilateral and multilateral sources:

(a) Information and methodologies:

(i) Improving data collection and information gathering, as well as their analysis, interpretation and dissemination to end-users;

(ii) Integrating climate change considerations into sustainable development planning;

(iii) Providing training in specialized fields relevant to adaptation such as climate and hydroclimate studies, geographical information systems, environmental impact assessment, modelling, integrated coastal zone management, soil and water conservation and soil restoration;

(iv) Strengthening existing and, where needed, establishing national and regional systematic observation and monitoring networks (sea-level rise, climate and hydrological monitoring stations, fire hazards, land degradation, floods, cyclones and droughts);

(v) Strengthening existing and, where needed, establishing national and regional centres and institutions for the provision of research, training, education and scientific and technical support in specialized fields relevant to climate change, utilizing information technology as much as possible;

(vi) Strengthening existing and, where needed, establishing national and regional research programmes on climate variability and climate change, oriented towards improving knowledge of the climate system at the regional level, and creating national and regional scientific capability; 
(vii) Supporting education and training in, and public awareness of, climate change related issues, for example through workshops and information dissemination;

(b) Vulnerability and adaptation:

(i) Supporting enabling activities for vulnerability and adaptation assessment;

(ii) Enhancing technical training for integrated climate change impact and vulnerability and adaptation assessments across all relevant sectors, and environmental management related to climate change;

(iii) Enhancing capacity, including institutional capacity, to integrate adaptation into sustainable development programmes;

(iv) Promoting the transfer of adaptation technologies;

(v) Establishing pilot or demonstration projects to show how adaptation planning and assessment can be practically translated into projects that will provide real benefits, and may be integrated into national policy and sustainable development planning, on the basis of information provided in the national communications from non-Annex I Parties and/or other relevant sources, and of the staged approach endorsed by the Conference of the Parties in its decision 11/CP.1;

(vi) Supporting capacity building, including institutional capacity, for preventive measures, planning, preparedness of disasters relating to climate change, including contingency planning, in particular, for droughts and floods in areas prone to extreme weather events;

(vii) Strengthening existing and, where needed, establishing early warning systems for extreme weather events in an integrated and interdisciplinary manner to assist developing country Parties, in particular those most vulnerable to climate change;

8. Decides that the implementation of the following activities shall be supported through the special climate change fund (in accordance with decision 7/CP.7) and/or the adaptation fund (in accordance with decision 10/CP.7), and other bilateral and multilateral sources:

(a) Starting to implement adaptation activities promptly where sufficient information is available to warrant such activities, inter alia, in the areas of water resources management, land management, agriculture, health, infrastructure development, fragile ecosystems, including mountainous ecosystems, and integrated coastal zone management;

(b) Improving the monitoring of diseases and vectors affected by climate change, and related forecasting and early-warning systems, and in this context improving disease control and prevention; 
English

Page 36

(c) Supporting capacity building, including institutional capacity, for preventive measures, planning, preparedness and management of disasters relating to climate change, including contingency planning, in particular, for droughts and floods in areas prone to extreme weather events;

(d) Strengthening existing and, where needed, establishing national and regional centres and information networks for rapid response to extreme weather events, utilizing information technology as much as possible;

9. Decides to consider, at its eighth session, the implementation of insurance-related actions to meet the specific needs and concerns of developing country Parties arising from the adverse effects of climate change, based on the outcome of the workshops referred to in paragraphs 37 and 38 below;

10. Requests the Subsidiary Body for Scientific and Technological Advice and the Subsidiary Body for Implementation to review, at their subsequent sessions, the progress of the abovementioned activities and make recommendations thereon to the Conference of the Parties at its eighth session;

\section{IMPLEMENTATION OF ARTICLE 4, PARAGRAPH 9, OF THE CONVENTION}

11. Decides to establish a work programme for the implementation of Article 4, paragraph 9, of the Convention, which would include activities covered under paragraphs 15 to 19 below, as well as the following:

(a) Strengthening existing and, where needed, establishing, national climate change secretariats and/or focal points to enable the effective implementation of the Convention and the Kyoto Protocol, in the least developed country Parties;

(b) Providing training, on an ongoing basis, in negotiating skills and language, where needed, to develop the capacity of negotiators from the least developed countries to participate effectively in the climate change process;

(c) Supporting the preparation of national adaptation programmes of action;

12. Decides that a least developed countries fund shall be established (in accordance with decision 7/CP.7), to be operated by an entity entrusted with the operation of the financial mechanism, under the guidance of the Conference of the Parties, to support the work programme for the least developed countries. This work programme shall include, inter alia, the preparation and implementation of national adaptation programmes of action;

13. Invites Annex II Parties to contribute financially to the programme mentioned in paragraph 11 above;

14. Invites Annex II Parties to support least developed country Parties for the following activities: 
(a) Promotion of public awareness programmes to ensure the dissemination of information on climate change issues;

(b) Development and transfer of technology, particularly adaptation technology (in accordance with decision 4/CP.7);

(c) Strengthening of the capacity of meteorological and hydrological services to collect, analyse, interpret and disseminate weather and climate information to support implementation of national adaptation programmes of action;

15. Decides that support be provided for the development, by the least developed countries, of national adaptation programmes of action which will serve as a simplified and direct channel of communication of information relating to the vulnerabilities and adaptation needs of the least developed countries; the information contained in national adaptation programmes of action may constitute the first step in the preparation of initial national communications;

16. Decides to consider, at its current session, the establishment of a least developed country group of experts, including its terms of reference, taking into account geographical balance, as well as the above-mentioned consideration of the terms of reference of the Consultative Group of Experts;

17. Decides to assess, at its current session, the status of implementation of Article 4, paragraph 9, of the Convention and to consider further action thereon;

\section{IMPACT OF THE IMPLEMENTATION OF RESPONSE MEASURES}

18. Stresses that Parties should take action consistent with the provisions of the Convention;

19. Decides that the implementation of the activities included in paragraphs 25 to 32 below shall be supported through the Global Environment Facility (in accordance with decision 6/CP.7), the special climate change fund (in accordance with decision 7/CP.7), and other bilateral and multilateral sources:

20. Encourages non-Annex I Parties to provide information, in their national communications and/or other relevant reports, on their specific needs and concerns arising from the impact of the implementation of response measures;

21. Requests Annex II Parties to provide detailed information, in their national communications and/or any other relevant reports, on their existing and planned support programmes to meet the specific needs and concerns of developing country Parties arising from the impact of the implementation of response measures;

22. Encourages Annex I and non-Annex I Parties to cooperate in creating favourable conditions for investment in sectors where such investment can contribute to economic diversification; 
23. Requests Annex II Parties to assist developing countries, in particular those most vulnerable to the impact of the implementation of response measures, in meeting their capacitybuilding needs for the implementation of programmes which address these impacts;

24. Urges Parties to consider appropriate technological options in addressing the impact of response measures, consistent with national priorities and indigenous resources;

25. Encourages Parties to cooperate in the technological development of non-energy uses of fossil fuels, and requests Annex II Parties to support developing country Parties to this end;

26. Encourages Parties to cooperate in the development, diffusion and transfer of less greenhouse gas-emitting advanced fossil-fuel technologies, and/or technologies relating to fossil fuels, that capture and store greenhouse gases, and requests Annex II Parties to facilitate the participation of the least developed countries and other non-Annex I Parties in this effort;

27. Urges Annex II Parties to provide financial and technological support for strengthening the capacity of developing country Parties identified in Article 4, paragraphs 8 and 9, of the Convention for improving efficiency in upstream and downstream activities relating to fossil fuels, taking into consideration the need to improve the environmental efficiency of these activities;

28. Encourages Annex II Parties to promote investment in, and to support and cooperate with, developing country Parties in the development, production, distribution and transport of indigenous, less greenhouse gas-emitting, environmentally sound, ${ }^{3}$ energy sources, including natural gas, according to the national circumstances of each of these Parties;

29. Urges Annex II Parties to provide support for research into, and the development and use of, renewable energy, including solar and wind energy, in developing country Parties;

30. Decides to consider, at its eighth session, the implementation of insurance-related actions to meet the specific needs and concerns of developing country Parties arising from the adverse effects of climate change, based on the outcome of the workshops referred to in paragraphs 37 and 38 below;

31. Requests the Subsidiary Body for Scientific and Technological Advice and the Subsidiary Body for Implementation to consider, at their subsequent sessions, the response by Parties to the actions listed in paragraphs 25 to 32 above;

\section{FURTHER MULTILATERAL WORK RELATING TO ISSUES UNDER ARTICLE 4, PARAGRAPHS 8 AND 9 OF THE CONVENTION}

32. Requests the secretariat to organize regional workshops in order to facilitate information exchange and integrated assessments, including for adaptation;

\footnotetext{
3 Throughout this decision, the term "environmentally sound" means "environmentally safe and sound" (Source: Agenda 21, chapter 1).
} 
33. Requests the secretariat to organize a workshop, before the eighth session of the Conference of the Parties, on the status of modelling activities to assess the adverse effects of climate change and the impact of response measures already implemented on individual developing country Parties, including on how to enhance the participation of developing country experts in such efforts, and to report the results of this workshop to the Conference of the Parties at its eighth session. The terms of reference of this workshop will include assessments on approaches to minimize the adverse effects of response measures on developing countries;

34. Requests the secretariat to organize a workshop, to be held immediately before the workshop referred to in paragraph 38 below, and before the eighth session of the Conference of the Parties, on insurance and risk assessment in the context of climate change and extreme weather events, and to report the results of this workshop to the Conference of the Parties at its eighth session;

35. Requests the secretariat to organize a workshop, to be held immediately after the workshop referred to in paragraph 37 above, and before the eighth session of the Conference of the Parties, on insurance-related actions to address the specific needs and concerns of developing country Parties arising from the adverse effects of climate change and from the impact of the implementation of response measures, and to report the results of this workshop to the Conference of the Parties at its eighth session;

36. Requests the secretariat to organize a workshop, before the ninth session of the Conference of the Parties, on possible synergies and joint action with the other multilateral environmental conventions and agreements, such as the United Nations Convention to Combat Desertification, and to report the results of this workshop to the Conference of the Parties at its ninth session;

37. Requests the secretariat to organize a workshop, before the ninth session of the Conference of the Parties, on the needs and options of non-Annex I Parties for economic diversification, and on support programmes by Annex II Parties to address these needs, and to report the results of this workshop to the Conference of the Parties at its ninth session; 


\title{
Decision 6/CP.7
}

\section{Additional guidance to an operating entity of the financial mechanism}

\author{
The Conference of the Parties,
}

Recalling its decisions 11/CP.1, 10/CP.2, 11/CP.2, 12/CP.2, 2/CP.4, 8/CP.5 and 10/CP.5,

Recalling further its decision 5/CP.6, containing the Bonn Agreements on the implementation of the Buenos Aires Plan of Action,

Noting the extension of funding through the expedited procedures of the Global Environment Facility (GEF) for countries to address capacity-building needs identified in decision 2/CP.4 enabling Parties to maintain and enhance relevant national capacities, and for the preparation of second national communications,

Noting also the launching of the GEF Country Dialogue Workshops, which have been designed to strengthen national coordination and capacity building and to promote awarenessraising, and the results of the first phase of the GEF Capacity Development Initiative, a strategic partnership between the GEF secretariat and the United Nations Development Programme, which were forwarded to Parties in accordance with decision 10/CP.5,

1. Decides that, in accordance with Articles 4.3, 4.5 and 11.1 of the Convention, the GEF, as an operating entity of the financial mechanism, should provide financial resources to developing country Parties, in particular the least developed and the small island developing States among them, for the following activities, including those identified in paragraph 7 of decision 5/CP.7:

(a) Strengthening, in particularly vulnerable countries and regions identified in stage I activities and especially countries vulnerable to climate-related natural disasters, the implementation of country-driven stage II adaptation activities, pursuant to decision 2/CP.4, paragraph 1 (a), that build upon work done at the national level, either in the context of national communications or of in-depth national studies, including national adaptation programmes of action (NAPAs);

(b) Establishing pilot or demonstration projects to show how adaptation planning and assessment can be practically translated into projects that will provide real benefits, and may be integrated into national policy and sustainable development planning, on the basis of information provided in the national communications, or of in-depth national studies, including NAPAs, and of the staged approach endorsed by the Conference of the Parties in its decision 11/CP.1;

(c) Supporting the continuation of the "country-team" approach, which enhances the collection, management, archiving, analysis, interpretation and dissemination of data on climate change issues and increases national commitment to the implementation of the objective of the Convention; 
(d) Enhancing the capacity of their subregional and/or regional information networks to enable such networks to serve as repositories of climate change related information on vulnerability and adaptation assessments and geographic information systems;

(e) Improving climate change related data collection (for example, local emission and regional factors) and information-gathering, as well as the analysis, interpretation and dissemination of these data to national policy makers and other end-users;

(f) Strengthening and, where necessary, establishing:

(i) National, subregional or regional databases on climate change;

(ii) Subregional and/or regional climate change related institutions and "centres of excellence", to enable these institutions and centres to provide a supportive framework, which would include information retrieval and technical support;

(g) Developing and implementing, as appropriate, prioritized projects identified in their national communications;

(h) Undertaking more in-depth public awareness and education activities and community involvement and participation in climate change issues;

(i) Building the capacity, including, where appropriate, institutional capacity, for preventive measures, planning, preparedness for disasters related to climate change, including in particular, contingency planning for droughts and floods in areas prone to extreme weather events;

(j) Strengthening existing and, where needed, establishing early warning systems for extreme weather events in an integrated and interdisciplinary manner to assist developing country Parties, in particular those most vulnerable to climate change;

(k) Supporting the continuation of GEF-related programmes which assist Parties that are at various stages of preparing and/or completing their initial national communications;

\section{Invites the GEF:}

(a) To continue its efforts to minimize the time between the approval of project concepts, the development and approval of the related projects, and the disbursement of funds by its implementing/executing agencies to the recipient countries of those projects;

(b) Further to streamline its project cycle with a view to making project preparations simpler, more transparent and country-driven. In this regard, the project cycles of its implementing/executing agencies should be coordinated with the GEF project cycle;

(c) To urge its implementing/executing agencies to be more responsive to requests for GEF assistance from developing country Parties for climate change related project activities aimed at implementing the guidance of the Conference of the Parties; 
(d) Further to encourage the use of national and regional experts and/or consultants to enhance project development and implementation; in this regard, it should make its list of national and regional experts and/or consultants publicly available;

(e) To give consideration to measures to increase opportunities available to developing country Parties for accessing GEF funds for climate change activities aimed at implementing the guidance of the Conference of the Parties, including a review of the adequacy of the number of implementing/executing agencies available to deliver GEF programmes and projects;

3. Urges the GEF to adopt a streamlined and expedited approach to financing activities within the framework for capacity-building in developing countries (non-Annex I Parties) contained in decision 2/CP.7;

4. Requests the GEF to include in its report to the Conference of the Parties at its eighth session the specific steps it has taken to implement the provisions of this decision and to include information on its implementation of the framework for capacity-building in developing countries (non-Annex I Parties) contained in decision 2/CP.7;

5. Requests the GEF, as an operating entity of the financial mechanism, to provide financial support to implement the capacity-building framework annexed to decision 2/CP.7 and further to support, enhance and implement its capacity-building activities in accordance with this framework. 


\section{Decision 7/CP.7}

\section{Funding under the Convention}

\section{The Conference of the Parties,}

Recalling the relevant provisions of the United Nations Framework Convention on Climate Change, and in particular its Articles 4.1, 4.3, 4.4, 4.5, 4.7, 4.8, 4.9, 4.10 and Article 11,

Recalling also its decisions 11/CP.1 and 15/CP.1,

Recalling further its decision 5/CP.6, containing the Bonn Agreements on the implementation of the Buenos Aires Plan of Action,

Noting that, by its decisions 2/CP.7, and 6/CP.7, provisions have been made for funding the implementation of capacity-building activities in Parties not included in Annex I, and that additional guidance has been given to the Global Environment Facility to that effect,

Welcoming the statements made at the second part of the sixth session by most Parties included in Annex II $^{1}$ on their willingness to commit themselves to provide funding,

Welcoming also the joint political declaration made by the European Community and its member States, together with Canada, Iceland, New Zealand, Norway and Switzerland, on their preparedness to contribute collectively $€ 450$ million / US\$ 410 million annually by 2005 , with this level to be reviewed in 2008 ,

1. Decides that:

(a) There is a need for funding, including funding that is new and additional to contributions which are allocated to the climate change focal area of the Global Environment Facility and to multilateral and bilateral funding, for the implementation of the Convention;

(b) Predictable and adequate levels of funding shall be made available to Parties not included in Annex I;

(c) In order to meet the commitments under Articles 4.1, 4.3, 4.4, 4.5, 4.8 and 4.9, Parties included in Annex II, and other Parties included in Annex I that are in a position to do so, should provide funding for developing country Parties, through the following channels:

(i) Increased Global Environment Facility replenishment;

(ii) The special climate change fund to be established under this decision;

(iii) The least developed countries fund to be established under this decision;

(iv) Bilateral and multilateral sources;

\footnotetext{
1 Joint political declaration by the European Community and its member States, together with Canada, Iceland, New Zealand, Norway and Switzerland, and a statement by Japan. For the text of the political declaration and the statement by Japan, see document FCCC/CP/2001/MISC.4.
} 
(d) Appropriate modalities for burden sharing among the Parties included in Annex II need to be developed;

(e) Parties included in Annex II shall report on their financial contributions on an annual basis;

(f) The Conference of the Parties shall review the reports referred to in subparagraph (e) above on an annual basis;

2. Decides also that a special climate change fund shall be established to finance activities, programmes and measures, relating to climate change, that are complementary to those funded by the resources allocated to the climate change focal area of Global Environment Facility and by bilateral and multilateral funding, in the following areas:

(a) Adaptation, in accordance with paragraph 8 of decision 5/CP.7;

(b) Transfer of technologies, in accordance with decision 4/CP.7;

(c) Energy, transport, industry, agriculture, forestry and waste management;

(d) Activities to assist developing country Parties referred to under Article 4, paragraph $8(\mathrm{~h})$, in diversifying their economies, in accordance with decision 5/CP.7;

3. Decides further that Parties included in Annex II, and other Parties included in Annex I that are in a position to do so, shall be invited to contribute to the fund, which shall be operated by an entity entrusted with the operation of the financial mechanism, under the guidance of the Conference of the Parties;

4. Invites the entity referred to in paragraph 3 above to make the necessary arrangements for this purpose and report thereon to the Conference of the Parties at its eighth session for appropriate action;

5. Decides to provide guidance to the entity referred to in paragraph 3 above on the modalities for operating this fund, including expedited access;

6. Decides also that a least developed countries fund shall be established, which shall be operated by an entity entrusted with the operation of the financial mechanism, under the guidance of the Conference of the Parties, to support a work programme for the least developed countries. This work programme shall include, inter alia, national adaptation programmes of action in accordance with Section II, "Implementation of Article 4, paragraph 9, of the Convention", of decision 5/CP.7;

7. Invites the entity referred to in paragraph 6 above to make the necessary arrangements for this purpose and report thereon to the Conference of the Parties at its eight session for appropriate action;

8. Decides to provide guidance to the entity referred to in paragraph 6 above on the modalities for operating this fund, including expedited access; 
FCCC/CP/2001/13/Add.1

English

Page 45

9. Welcomes the intention expressed by Canada to contribute $\mathrm{C} \$ 10$ million, to enable the prompt start of this fund.

$8^{\text {th }}$ plenary meeting 10 November 2001 


\section{Decision 8/CP.7}

\section{Activities implemented jointly under the pilot phase}

\section{The Conference of the Parties,}

Recalling its decisions 5/CP.1 and 13/CP.5,

Recalling further its decision 5/CP.6, containing the Bonn Agreements on the implementation of the Buenos Aires Plan of Action,

Taking note of the fourth synthesis report on activities implemented jointly under the pilot phase $^{1}$ and the draft revised uniform reporting format, ${ }^{2}$

Having considered the conclusions of the Subsidiary Body for Scientific and Technological Advice and the Subsidiary Body for Implementation at the first part of their thirteenth sessions, ${ }^{3}$

Acknowledging that participating in activities implemented jointly under the pilot phase provides an important opportunity for learning by doing,

Further acknowledging the importance of offering opportunities to participate in activities implemented jointly under the pilot phase to those Parties that have not yet experienced such activities,

Noting that the geographical distribution of activities implemented jointly under the pilot phase remains unbalanced despite recent improvements,

1. Decides to continue the pilot phase for activities implemented jointly;

2. Requests the secretariat to organize before the sixteenth sessions of the subsidiary bodies a workshop on the draft revised uniform reporting format providing an opportunity to Parties to exchange views on and understand further the methodological issues related to the format;

\footnotetext{
$1 \mathrm{FCCC} / \mathrm{SB} / 2000 / 6$.

2 FCCC/SB/2000/6/Add.1.

3 FCCC/SBSTA/2000/10 and FCCC/SBI/2000/10.
} 
FCCC/CP/2001/13/Add.1

English

Page 47

3. Urges Parties reporting on activities implemented jointly under the pilot phase to submit joint reports through the designated national authority of one Party, which should provide proof that the designated national authorities of all the other Parties involved concur with the reports.

$8^{\text {th }}$ plenary meeting

10 November 2001 


\section{Decision 9/CP.7}

\section{Matters relating to Article 3, paragraph 14, of the Kyoto Protocol}

The Conference of the Parties,

Having considered matters relating to Article 3, paragraph 14, of the Kyoto Protocol,

Recalling its decision 8/CP.4, particularly as it refers to decision 5/CP.4,

Recalling further its decision 5/CP.6, containing the Bonn Agreements on the implementation of the Buenos Aires Plan of Action,

Recommends that the Conference of the Parties serving as the meeting of the Parties to the Kyoto Protocol, at its first session, adopt draft decision -/CMP.1 (Matters relating to Article 3, paragraph 14, of the Kyoto Protocol) below.

$8^{\text {th }}$ plenary meeting 10 November 2001

\section{Draft decision -/CMP.1 (Matters relating to Article 3, paragraph 14, of the Kyoto Protocol)}

\section{Matters relating to Article 3, paragraph 14, of the Kyoto Protocol}

The Conference of the Parties serving as the meeting of the Parties to the Kyoto Protocol,

Determined to protect the climate system for present and future generations,

Having considered matters relating to Article 3, paragraph 14, of the Kyoto Protocol,

Recalling decisions 8/CP.4 and 5/CP.4,

Recalling also decisions 5/CP.4 and 12/CP.5,

Reiterating that the extent to which developing country Parties will effectively implement their commitments will depend on the effective implementation by the developed country Parties of their commitments related to financial resources and transfer of technology and will take fully into account that economic and social development and poverty eradication are the first and overriding priorities of the developing country Parties, 
Reiterating that Parties should protect the climate system for the benefit of present and future generations of humankind, on the basis of equity and in accordance with their common but differentiated responsibilities and respective capabilities and, accordingly, that the developed country Parties should take the lead in combating climate change and the adverse effects thereof,

Recognizing that developing country Parties that would have to bear a disproportionate or abnormal burden under the Convention should be given full consideration,

Recognizing that low-lying and other small island countries, countries with low-lying coastal, arid and semi-arid areas or areas liable to floods, drought and desertification, and developing countries with fragile mountainous ecosystems, are particularly vulnerable to the adverse effects of climate change,

Recognizing the special difficulties of those countries, especially developing countries, whose economies are particularly dependent on fossil fuel production, use and exportation, as a consequence of action taken to limit greenhouse gas emissions,

1. Decides to establish a process for the implementation of Article 3, paragraph 14, of the Kyoto Protocol, including exchange of information and the development of methodologies on the assessment of adverse social, environmental and economic impacts on developing country Parties, particularly those identified in Article 4, paragraphs 8 and 9, of the Convention, and of their minimization; among the issues to be considered shall be the establishment of funding, insurance and transfer of technology;

2. Recognizes that minimizing the impact of the implementation of Article 3, paragraph 1, of the Kyoto Protocol is a development concern affecting both the industrialized and developing countries. Each Party included in Annex I commits itself to take fully into account the consequences of these actions on developing countries, and to prevent or minimize their adverse effects on developing countries; these Parties consider such action as a cost-effectiveness measure;

3. Requests each Party included in Annex I to provide information, as part of the necessary supplementary information to its annual inventory report, in accordance with the guidelines under Article 7, paragraph 1, of the Kyoto Protocol, relating to how it is striving, under Article 3, paragraph 14, of the Kyoto Protocol, to implement the commitments mentioned in Article 3, paragraph 1, of the Kyoto Protocol in such a way as to minimize adverse social, environmental and economic impacts on developing country Parties, particularly those identified in Article 4, paragraphs 8 and 9, of the Convention; and further requests those Parties to incorporate, in this respect, information on action identified in paragraph 8 below, based on methodologies identified at the workshop referred to in paragraph 11 below;

4. Decides that the information referred to in paragraph 3 above shall be considered by the facilitative branch of the compliance committee;

5. Invites Parties not included in Annex I to provide information on their specific needs and concerns related to the adverse social, environmental and economic impacts arising from the implementation of commitments under Article 3, paragraph 1, of the Kyoto Protocol, and requests Parties included in Annex II to the Convention to provide support for that purpose; 
English

Page 50

6. Decides to develop guidelines before the second session of the Conference of the Parties serving as the meeting of the Parties to the Kyoto Protocol to help determine if Parties included in Annex I are striving to minimize adverse effects, including the adverse effects of climate change, effects on international trade, and social, environmental and economic impacts on other Parties, especially developing country Parties, and in particular those identified in Article 4, paragraphs 8 and 9, of the Convention, based on methodologies identified at the workshop referred to in paragraph 11 below;

7. Invites the Intergovernmental Panel on Climate Change, in cooperation with other relevant organizations, to prepare a technical paper on geological carbon storage technologies, covering current information, and report on it for the consideration of the Conference of the Parties serving as the meeting of the Parties to the Kyoto Protocol at its second session;

8. Agrees that Parties included in Annex II to the Convention, and other Parties included in Annex I in a position to do so, should give priority, in implementing their commitments under Article 3, paragraph 14, of the Kyoto Protocol, to the following actions:

(a) The progressive reduction or phasing out of market imperfections, fiscal incentives, tax and duty exemptions and subsidies in all greenhouse gas emitting sectors, taking into account the need for energy price reforms to reflect market prices and externalities, in pursuit of the objective of the Convention;

(b) Removing subsidies associated with the use of environmentally unsound and unsafe technologies;

(c) Cooperating in the technological development of non-energy uses of fossil fuels, and supporting developing country Parties to this end;

(d) Cooperating in the development, diffusion and transfer of less greenhouse gasemitting advanced fossil-fuel technologies, and/or technologies relating to fossil fuels that capture and store greenhouse gases, and encouraging their wider use; and facilitating the participation of the least developed countries and other Parties not included in Annex I in this effort;

(e) Strengthening the capacity of developing country Parties identified in Article 4, paragraphs 8 and 9, of the Convention for improving efficiency in upstream and downstream activities relating to fossil fuels, taking into consideration the need to improve the environmental efficiency of these activities;

(f) Assisting developing country Parties which are highly dependent on the export and consumption of fossil fuels in diversifying their economies;

9. Encourages Parties included in Annex I to adopt policies and measures that will result in reductions in emissions of greenhouse gases, as an effective contribution to minimizing the adverse effects of climate change, and to provide information on these policies and measures in their national communications; 
10. Decides to review the actions taken by Parties included in Annex I, in accordance with this decision, and to consider, at its third session, what further actions are necessary; among the issues to be considered shall be the establishment of funding, insurance and transfer of technology, pursuant to Article 3, paragraph 14;

11. Requests the secretariat to organize, before the second session of the Conference of the Parties serving as the meeting of the Parties to the Kyoto Protocol, a workshop on reporting methodologies on ways to minimize adverse social, environmental and economic impacts on developing country Parties of the implementation of policies and measures by Parties included in Annex I in achieving their quantified emission limitation and reduction commitments under Article 3, paragraph 1;

12. Requests the Subsidiary Body for Scientific and Technological Advice and the Subsidiary Body for Implementation to consider the output of the workshop referred to in paragraph 11 above, and to make recommendations thereon to the second session of the Conference of the Parties serving as the meeting of the Parties to the Kyoto Protocol. 


\section{Decision 10/CP.7}

\section{Funding under the Kyoto Protocol}

\section{The Conference of the Parties,}

Recalling Articles 10, 11 and 12, paragraph 8, of the Kyoto Protocol,

Recalling also its decisions 11/CP.1 and 15/CP.1,

Recalling further its decision 5/CP.6, containing the Bonn Agreements on the implementation of the Buenos Aires Plan of Action,

Recognizing that funding should be made available to Parties not included in Annex I which is new and additional to contributions under the Convention,

Recognizing also that appropriate modalities for burden sharing need to be developed,

Welcoming the statements made at the second part of the sixth session of the Conference of the Parties by most Parties included in Annex $\mathrm{II}^{1}$ on their willingness to commit themselves to provide funding,

Welcoming also the joint political declaration made by the European Community and its member States, together with Canada, Iceland, New Zealand, Norway and Switzerland, on their preparedness to collectively contribute $€ 450$ million/US $\$ 410$ million annually by 2005 , with this level to be reviewed in 2008 ,

1. Decides that an adaptation fund shall be established to finance concrete adaptation projects and programmes in developing country Parties that are Parties to the Protocol, as well as activities identified in paragraph 8 of decision 5/CP.7;

2. Decides also that the adaptation fund shall be financed from the share of proceeds on the clean development mechanism project activities and other sources of funding;

3. Decides further that Parties included in Annex I that intend to ratify the Kyoto Protocol are invited to provide funding, which will be additional to the share of proceeds on clean development mechanism project activities;

4. Decides also that the adaptation fund shall be operated and managed by an entity entrusted with the operation of the financial mechanism of the Convention, under the guidance of the Conference of the Parties serving as the meeting of the Parties to the Kyoto Protocol, with guidance to be provided by the Conference of the Parties in the period prior to entry into force of the Kyoto Protocol;

\footnotetext{
1 Joint political declaration by the European Community and its member States, together with Canada, Iceland, New Zealand, Norway and Switzerland, and a statement by Japan. For the text of the political declaration and the statement by Japan see document FCCC/CP/2001/MISC.4.
} 
FCCC/CP/2001/13/Add.1

English

Page 53

5. Invites the entity referred to in paragraph 4 above to make the necessary arrangements for this purpose;

6. Decides that Parties included in Annex I that intend to ratify the Kyoto Protocol shall report on their financial contributions to the fund on an annual basis;

7. Decides also to review the reports referred to in paragraph 6 above on an annual basis, and that, upon entry into force of the Kyoto Protocol, such reports are to be reviewed by the Conference of the Parties serving as the meeting of the Parties to the Kyoto Protocol.

$8^{\text {th }}$ plenary meeting

10 November 2001 


\section{Decision 11/CP.7}

\section{Land use, land-use change and forestry}

The Conference of the Parties,

Recalling its decisions 1/CP.4, 8/CP.4, 9/CP.4 and 16/CP.5,

Recalling also its decision 5/CP.6, containing the Bonn Agreements on the implementation of the Buenos Aires Plan of Action,

Acknowledging with appreciation the scientific advice provided in the Special Report on Land use, Land-use Change and Forestry prepared by the Intergovernmental Panel on Climate Change,

1. Recommends that the Conference of the Parties serving as the meeting of the Parties to the Kyoto Protocol, at its first session, adopt draft decision -/CMP.1 (Land use, landuse change and forestry) below;

2. Requests the Subsidiary Body for Scientific and Technological Advice (SBSTA):

(a) To consider, following the completion of the methodological work by the Intergovernmental Panel on Climate Change (IPCC) as outlined in paragraph 3 (c) below, and adopt methodologies to account for anthropogenic greenhouse gas emissions resulting from direct human-induced degradation and devegetation activities, with a view to the Conference of the Parties at its tenth session recommending a decision for adoption by the Conference of the Parties serving as the meeting of the Parties to the Kyoto Protocol at its first session regarding whether such activities should be included in the first commitment period;

(b) To investigate the possible application of biome-specific forest definitions for the second and subsequent commitment periods with a view to the Conference of the Parties at its tenth session recommending a decision for adoption on the use of such biome-specific forest definitions for future commitment periods to the Conference of the Parties serving as the meeting of the Parties to the Kyoto Protocol at its first session;

(c) To incorporate the work of the IPCC as outlined in paragraph 3 (d) below into any revisions of modalities, rules and guidelines prior to the second commitment period, for the accounting of activities under Article 3.4 of the Kyoto Protocol;

(d) To develop at its sixteenth session terms of reference for the work to be conducted under paragraph 2 (e) below;

(e) To develop definitions and modalities for including afforestation and reforestation project activities under Article 12 in the first commitment period, taking into account the issues of non-permanence, additionality, leakage, uncertainties and socio-economic and environmental impacts, including impacts on biodiversity and natural ecosystems, and being guided by the principles in the preamble to draft decision -/CMP.1 (Land use, land-use change and forestry) 
attached hereto and the terms of reference referred to in paragraph 2 (d) above, with the aim of adopting a decision on these definitions and modalities at the ninth session of the Conference of the Parties, to be forwarded to the Conference of the Parties serving as the meeting of the Parties to the Kyoto Protocol at its first session;

3. Invites the Intergovernmental Panel on Climate Change (IPCC):

(a) To elaborate methods to estimate, measure, monitor, and report changes in carbon stocks and anthropogenic greenhouse gas emissions by sources and removals by sinks resulting from land use, land-use change and forestry activities under Article 3, paragraphs 3 and 4, and Articles 6 and 12 of the Kyoto Protocol, on the basis of the Revised 1996 Intergovernmental Panel on Climate Change Guidelines for National Greenhouse Gas Inventories, taking into account the present decision (11/CP.7) and draft decision -/CMP.1 (Land use, land-use change and forestry) attached hereto, to be submitted for consideration and possible adoption to the Conference of the Parties at its ninth session;

(b) To prepare a report on good practice guidance and uncertainty management relating to the measurement, estimation, assessment of uncertainties, monitoring and reporting of net carbon stock changes and anthropogenic greenhouse gas emissions by sources and removals by sinks in the land use, land-use change and forestry sector, taking into consideration the present decision (11/CP.7) and draft decision -/CMP.1 (Land use, land-use change and forestry) attached hereto, to be submitted for consideration and possible adoption to the Conference of the Parties at its ninth session;

(c) To develop definitions for direct human-induced 'degradation' of forests and 'devegetation' of other vegetation types and methodological options to inventory and report on emissions resulting from these activities, to be submitted for consideration and possible adoption to the Conference of the Parties at its ninth session; and,

(d) To develop practicable methodologies to factor out direct human-induced changes in carbon stocks and greenhouse gas emissions by sources and removals by sinks from changes in carbon stocks and greenhouse gas emissions by sources and removals by sinks due to indirect human-induced and natural effects (such as those from carbon dioxide fertilization and nitrogen deposition), and effects due to past practices in forests (pre-reference year), to be submitted to the Conference of the Parties at its tenth session;

4. Decides that any changes to the treatment of harvested wood products shall be in accordance with future decisions of the Conference of the Parties. 


\section{Draft decision -/CMP.1 (Land use, land-use change and forestry)}

\section{Land use, land-use change and forestry}

The Conference of the Parties serving as the meeting of the Parties to the Kyoto Protocol,

Affirming that the implementation of land use, land-use change and forestry activities included under the provisions of the Kyoto Protocol shall be consistent with the objectives and principles of, and any decisions taken under, the United Nations Framework Convention on Climate Change and its Kyoto Protocol,

Having considered decision 11/CP.7 adopted by the Conference of the Parties at its seventh session,

1. Affirms that the following principles govern the treatment of land use, land-use change and forestry activities:

(a) That the treatment of these activities be based on sound science;

(b) That consistent methodologies be used over time for the estimation and reporting of these activities;

(c) That the aim stated in Article 3, paragraph 1 of the Kyoto Protocol not be changed by accounting for land use, land-use change and forestry activities;

(d) That the mere presence of carbon stocks be excluded from accounting;

(e) That the implementation of land use, land-use change and forestry activities contributes to the conservation of biodiversity and sustainable use of natural resources;

(f) That accounting for land use, land-use change and forestry does not imply a transfer of commitments to a future commitment period;

(g) That reversal of any removal due to land use, land-use change and forestry activities be accounted for at the appropriate point in time;

(h) That accounting excludes removals resulting from: (i) elevated carbon dioxide concentrations above their pre-industrial level; (ii) indirect nitrogen deposition; and (iii) the dynamic effects of age structure resulting from activities and practices before the reference year;

2. Decides that good practice guidance, and methods to estimate, measure, monitor and report changes in carbon stocks and anthropogenic greenhouse gas emissions by sources and removals by sinks resulting from land use, land-use change and forestry activities, as developed by the Intergovernmental Panel on Climate Change, shall be applied by Parties, if decided in accordance with relevant decisions of the Conference of the Parties and the Conference of the Parties serving as the meeting of the Parties to the Kyoto Protocol;

3. Decides that anthropogenic greenhouse gas emissions by sources and removals by sinks shall be accounted for in accordance with the annex to the present decision and reported in 
annual inventories and reviewed in accordance with relevant decisions relating to Articles 5, 7 and 8 of the Kyoto Protocol, and in accordance with the Revised 1996 IPCC Guidelines for National Greenhouse Gas Inventories, any future elaboration of these guidelines, or parts of them, and any good practice guidance on land-use change and forestry in accordance with relevant decisions of the Conference of the Parties and the Conference of the Parties serving as the meeting of the Parties to the Kyoto Protocol;

4. Adopts the definitions, modalities, rules and guidelines relating to land use, landuse change and forestry activities under Articles 3, 6 and 12 of the Kyoto Protocol contained in the attached annex for application in the first commitment period. 


\section{ANNEX}

\section{Definitions, modalities, rules and guidelines relating to land use, land-use change and forestry activities under the Kyoto Protocol}

\section{A. Definitions}

1. For land use, land-use change and forestry activities under Article ${ }^{1} 3$, paragraphs 3 and 4 , the following definitions shall apply:

(a) "Forest" is a minimum area of land of 0.05-1.0 hectares with tree crown cover (or equivalent stocking level) of more than 10-30 per cent with trees with the potential to reach a minimum height of 2-5 metres at maturity in situ. A forest may consist either of closed forest formations where trees of various storeys and undergrowth cover a high proportion of the ground or open forest. Young natural stands and all plantations which have yet to reach a crown density of 10-30 per cent or tree height of 2-5 metres are included under forest, as are areas normally forming part of the forest area which are temporarily unstocked as a result of human intervention such as harvesting or natural causes but which are expected to revert to forest;

(b) "Afforestation" is the direct human-induced conversion of land that has not been forested for a period of at least 50 years to forested land through planting, seeding and/or the human-induced promotion of natural seed sources;

(c) "Reforestation" is the direct human-induced conversion of non-forested land to forested land through planting, seeding and/or the human-induced promotion of natural seed sources, on land that was forested but that has been converted to non-forested land. For the first commitment period, reforestation activities will be limited to reforestation occurring on those lands that did not contain forest on 31 December 1989;

(d) "Deforestation" is the direct human-induced conversion of forested land to nonforested land;

(e) "Revegetation" is a direct human-induced activity to increase carbon stocks on sites through the establishment of vegetation that covers a minimum area of 0.05 hectares and does not meet the definitions of afforestation and reforestation contained here;

(f) "Forest management" is a system of practices for stewardship and use of forest land aimed at fulfilling relevant ecological (including biological diversity), economic and social functions of the forest in a sustainable manner;

(g) "Cropland management" is the system of practices on land on which agricultural crops are grown and on land that is set aside or temporarily not being used for crop production;

(h) "Grazing land management" is the system of practices on land used for livestock production aimed at manipulating the amount and type of vegetation and livestock produced.

\footnotetext{
1 "Article" in this annex refers to an Article of the Kyoto Protocol, unless otherwise specified.
} 


\section{B. Article 3, paragraph 3}

2. For the purposes of Article 3, paragraph 3, eligible activities are those direct humaninduced afforestation, reforestation and/or deforestation activities that meet the requirements set forth in this annex and that started on or after 1 January 1990 and before 31 December of the last year of the commitment period.

3. For the purposes of determining the area of deforestation to come into the accounting system under Article 3, paragraph 3, each Party shall determine the forest area using the same spatial assessment unit as is used for the determination of afforestation and reforestation, but not larger than 1 hectare.

4. For the first commitment period, debits ${ }^{2}$ resulting from harvesting during the first commitment period following afforestation and reforestation since 1990 shall not be greater than credits $^{3}$ accounted for on that unit of land.

5. Each Party included in Annex I shall report, in accordance with Article 7, on how harvesting or forest disturbance that is followed by the re-establishment of a forest is distinguished from deforestation. This information will be subject to review in accordance with Article 8.

\section{Article 3, paragraph 4}

6. A Party included in Annex I may choose to account for anthropogenic greenhouse gas emissions by sources and removals by sinks resulting from any or all of the following humaninduced activities, other than afforestation, reforestation and deforestation, under Article 3, paragraph 4, in the first commitment period: revegetation, forest management, cropland management, and grazing land management.

7. A Party included in Annex I wishing to account for activities under Article 3, paragraph 4, shall identify, in its report to enable the establishment of its assigned amount pursuant to Article 3.7 and Article 3.8, the activities under Article 3, paragraph 4, which it elects to include in its accounting for the first commitment period. Upon election, a decision by a Party will be fixed for the first commitment period.

8. During the first commitment period, a Party included in Annex I that selects any or all of the activities mentioned in paragraph 6 above shall demonstrate that such activities have occurred since 1990 and are human-induced. A Party included in Annex I shall not account for emissions by sources and removals by sinks resulting from activities under Article 3, paragraph 4, if these are already accounted for under Article 3, paragraph 3.

9. For the first commitment period, accountable anthropogenic greenhouse gas emissions by sources and removals by sinks resulting from cropland management, grazing land management and revegetation under Article 3, paragraph 4, shall be equal to anthropogenic greenhouse gas

2 'Debits': where emissions are larger than removals on a unit of land.

3 'Credits': where removals are larger than emissions on a unit of land. 
English

Page 60

emissions by sources and removals by sinks in the commitment period, less five times the anthropogenic greenhouse gas emissions by sources and removals by sinks resulting from these eligible activities in the base year of that Party, while avoiding double accounting.

10. For the first commitment period, a Party included in Annex I that incurs a net source of emissions under the provisions of Article 3, paragraph 3, may account for anthropogenic greenhouse gas emissions by sources and removals by sinks in areas under forest management under Article 3, paragraph 4, up to a level that is equal to the net source of emissions under the provisions of Article 3.3, but not greater than 9.0 megatons of carbon times five, if the total anthropogenic greenhouse gas emissions by sources and removals by sinks in the managed forest since 1990 is equal to, or larger than, the net source of emissions incurred under Article 3, paragraph 3.

11. For the first commitment period only, additions to and subtractions from the assigned amount of a Party ${ }^{4}$ resulting from forest management under Article 3, paragraph 4, after the application of paragraph 10 above and resulting from forest management project activities undertaken under Article 6, shall not exceed the value inscribed in the appendix ${ }^{5}$ below, times five.

12. A Party may request the Conference of the Parties to reconsider its numerical values as contained in paragraph 10 and in the appendix to paragraph 11, with a view to the Conference of the Parties recommending a decision for adoption to the Conference of the Parties serving as the meeting of the Parties to the Kyoto Protocol, no later than 2 years prior to the beginning of the first commitment period. Such a reconsideration shall be based upon country-specific data and the elements of guidance and consideration in footnote 5 to paragraph 11 . These shall be submitted and reviewed in accordance with relevant decisions related to Articles 5, 7 and 8 of the Kyoto Protocol, and in accordance with the Revised 1996 Intergovernmental Panel on Climate Change Guidelines for National Greenhouse Gas Inventories, any future elaboration of these guidelines, or parts of them, and any good practice guidance on land use, land-use change and forestry in accordance with the relevant decisions of the Conference of the Parties.

\section{D. $\underline{\text { Article } 12}$}

13. The eligibility of land use, land-use change and forestry project activities under Article 12 is limited to afforestation and reforestation.

\footnotetext{
4 In accordance with decision -/CMP.1 (Modalities for the accounting of assigned amounts).

5 In arriving at the values in the appendix below, the Conference of the Parties was guided by the application of an 85 per cent discount factor to account for the removals identified in paragraph 1(h) of decision -/CMP.1 (Land use, land-use change and forestry) and a 3 per cent cap on forest management, using a combination of data provided by Parties and by the Food and Agriculture Organization (FAO). Consideration was also given to national circumstances (including the degree of effort needed to meet Kyoto commitments and the forest management measures implemented). The accounting framework established in this paragraph shall not be construed as establishing any precedent for the second and subsequent commitment periods.
} 
14. For the first commitment period, the total of additions to a Party's assigned amount resulting from eligible land use, land-use change and forestry project activities under Article 12 shall not exceed one per cent of base year emissions of that Party, times five.

15. The treatment of land use, land-use change and forestry project activities under Article 12 in future commitment periods shall be decided as part of the negotiations on the second commitment period.

\section{E. General}

16. Each Party included in Annex I shall, for the purposes of applying the definition of "forest" as contained in paragraph 1(a) above, select a single minimum tree crown cover value between 10 and 30 per cent, a single minimum land area value between 0.05 and 1 hectare and a single minimum tree height value between 2 and 5 metres. The selection of a Party shall be fixed for the duration of the first commitment period. The selection shall be included as an integral part of its report to enable the calculation of its assigned amount pursuant to Article 3, paragraphs 7 and 8 in accordance with decision 19/CP.7, and shall include the values for tree crown cover, tree height and the minimum land area. Each Party shall justify in its reporting that such values are consistent with the information that has historically been reported to the Food and Agriculture Organization of the United Nations or other international bodies, and if they differ, explain why and how such values were chosen.

17. For the first commitment period, and subject to other provisions in this annex, the additions to and subtractions from the assigned amount of a Party pursuant to Article 3 , paragraphs 7 and 8 shall be equal to anthropogenic greenhouse gas emissions by sources and removals by sinks measured as verifiable changes in carbon stocks, and non-carbon dioxide greenhouse gas emissions during the period 1 January 2008 to 31 December 2012 resulting from afforestation, reforestation and deforestation under Article 3.3 and forest management under Article 3, paragraph 4, that have taken place since 1 January 1990. Where the result of this calculation is a net sink of greenhouse gases, this value shall be added to the assigned amount of that Party. Where the result of this calculation is a net source of greenhouse gas emissions, this value shall be subtracted from the assigned amount of that Party.

18. Accounting of anthropogenic greenhouse gas emissions by sources and removals by sinks resulting from land use, land-use change and forestry activities under Article 3, paragraphs 3 and 4 , shall begin with the onset of the activity or the beginning of the commitment period, whichever comes later.

19. Once land is accounted for under Article 3, paragraphs 3 and 4, all anthropogenic greenhouse gas emissions by sources from and removals by sinks on this land must be accounted for throughout subsequent and contiguous commitment periods.

20. National inventory systems under Article 5.1 shall ensure that areas of land subject to land use, land-use change and forestry activities under Article 3, paragraphs 3 and 4 are identifiable, and information about these areas should be provided by each Party included in Annex I in their national inventories in accordance with Article 7. Such information will be reviewed in accordance with Article 8. 
FCCC/CP/2001/13/Add.1

English

Page 62

21. Each Party included in Annex I shall account for all changes in the following carbon pools: above-ground biomass, below-ground biomass, litter, dead wood, and soil organic carbon. A Party may choose not to account for a given pool in a commitment period, if transparent and verifiable information is provided that the pool is not a source. 
FCCC/CP/2001/13/Add.1

English

Page 63

\section{APPENDIX $^{6}$}

\begin{tabular}{|l|c|}
\hline \multicolumn{1}{|c|}{ Party } & Mt C/yr \\
\hline Australia & 0.00 \\
Austria & 0.63 \\
Belarus & \\
Belgium & 0.03 \\
Bulgaria & 0.37 \\
Canada & 12.00 \\
Croatia & \\
Czech Republic & 0.32 \\
Denmark & 0.05 \\
Estonia & 0.10 \\
Finland & 0.16 \\
France & 0.88 \\
Germany & 1.24 \\
Greece & 0.09 \\
Hungary & 0.29 \\
Iceland & 0.00 \\
Ireland & 0.05 \\
Italy & 0.18 \\
Japan & 13.00 \\
Latvia & 0.34 \\
Liechtenstein & 0.01 \\
Lithuania & 0.28 \\
Luxembourg & 0.01 \\
Monaco & 0.00 \\
Netherlands & 0.01 \\
New Zealand & 0.20 \\
Norway & 0.40 \\
Poland & 0.82 \\
Portugal & 0.22 \\
Romania & 1.10 \\
Russian Federation & 0.53 \\
Slovakia & 0.36 \\
Slovenia & 0.67 \\
Spain & 0.58 \\
Sweden & 0.50 \\
Switzerland & 1.11 \\
Ukraine & 0.37 \\
United Kingdom & \\
\hline
\end{tabular}

6 The list of countries in this table differs from that found in decision 5/CP.6 as a result of consultations undertaken during the session.

7 This figure is changed to $33.00 \mathrm{Mt} / \mathrm{C} / \mathrm{yr}$ by decision 12/CP.7 (Forest management activities under Article 3, paragraph 4, of the Kyoto Protocol: the Russian Federation). 


\section{Decision 12/CP.7}

\section{Forest management activities under Article 3, paragraph 4, of the Kyoto Protocol: the Russian Federation}

The Conference of the Parties,

Recalling its decision 5/CP.6, containing the Bonn Agreements on the implementation of the Buenos Aires Plan of Action,

Recalling also the relevant provisions of decision 11/CP.7 and in particular, paragraphs 10 and 11 of the annex to decision -/CMP.1 (Land use, land-use change and forestry), attached thereto,

Having considered a submission by the Russian Federation ${ }^{1}$ with regard to the value stated for this Party in the appendix to the above-mentioned annex,

Decides that, for the first commitment period, additions to and subtractions from the assigned amount of the Russian Federation, resulting from forest management under Article 3.4 after the application of paragraph 10 of the above-mentioned annex, and resulting from forest management projects under Article 6, shall not exceed 33 megatons of carbon per year, times five. $^{2}$

1 See FCCC/CP/2001/MISC.6.

2 This corrects an error in the appendix to the draft decision on land use, land-use change and forestry in document FCCC/CP/2001/5/Add.2. 


\section{Decision 13/CP.7}

\section{“Good practices" in policies and measures among Parties included in Annex I to the Convention ${ }^{1}$}

\section{The Conference of the Parties,}

Recalling the relevant provisions of the United Nations Framework Convention on Climate Change, in particular in Articles 4 and 7, paragraph 2(b), and of the Kyoto Protocol, in particular in Articles 2, 3 and 7,

Recalling also its decision 8/CP.4 whereby it requested the Subsidiary Body for Scientific and Technological Advice to undertake preparatory work to enable the Conference of the Parties serving as the meeting of the Parties to the Kyoto Protocol, at its first session after the entry into force of the Kyoto Protocol, to consider ways to facilitate cooperation to enhance the individual and combined effectiveness of policies and measures under Article 2, paragraph 1(b), of the Kyoto Protocol,

Recalling further its decision 5/CP.6, containing the Bonn Agreements on the implementation of the Buenos Aires Plan of Action,

Noting the Chairman's reports on the workshops held in Copenhagen from 11 to 13 April $2000,{ }^{2}$ pursuant to decision $8 / C P .4$, and from 8 to 10 October $2001,{ }^{3}$ pursuant to the request by the Conference of the Parties at the first part of its sixth session, ${ }^{4}$

Appreciative of the contribution of the Governments of Denmark and France and Norway in sponsoring these workshops,

Recognizing that the implementation of policies and measures contributes to achieving the objectives of the Convention and the Kyoto Protocol,

Recognizing also the value of information exchanges on "good practices" in policies and measures which are based on national circumstances, in furthering the objectives of the Convention and the Kyoto Protocol,

1. Decides, in making preparations during the lead-up to the first session of the Conference of the Parties serving as the meeting of the Parties to the Kyoto Protocol, in relation to Article 2, paragraph 1(b), of the Kyoto Protocol, to continue to facilitate cooperation among

1 In the context of this decision, the term "good practice" replaces the term "best practice".

2 FCCC/SBSTA/2000/2.

$3 \quad$ FCCC/CP/SBSTA/2001/INF.5

4 FCCC/CP/200/5/Add.2, section III. F. 
English

Page 66

Parties included in Annex I to the Convention (Annex I Parties) in order to enhance the individual and combined effectiveness of policies and measures such as those in Article 2, paragraph 1(a), of the Kyoto Protocol, in particular by sharing experience and exchanging information at a technical level, and taking into account national circumstances;

2. Decides further that the work referred to in paragraph 1 above should take place under the guidance of the Subsidiary Body for Scientific and Technological Advice (SBSTA), inter alia through initiatives involving all Parties and, as appropriate, environmental and business non-governmental organizations, and should include the exchange of information on policies and measures undertaken by Annex I Parties in all relevant sectors and on cross-cutting and methodological issues;

3. Decides that this work should contribute to the improvement of transparency, effectiveness and comparability of policies and measures. To that end this work should:

(a) Enhance transparency in reporting on policies and measures in the national communications of Annex I Parties through, as appropriate, criteria and quantitative parameters, and consider issues of methodology, attribution, and national circumstances;

(b) Facilitate information sharing on ways Annex I Parties have striven to implement policies and measures in such a way as to minimize adverse effects, including the adverse effects of climate change, effects on international trade, and social, environmental and economic impacts on developing country Parties, taking into account information related to these issues provided by Parties not included in Annex I to the Convention (non-Annex I Parties);

(c) Assist Parties and the Conference of the Parties in identifying further options for cooperation between Annex I Parties and other interested Parties to enhance the individual and combined effectiveness of their policies and measures;

4. Decides also that this work should contribute to the elaboration of elements for reporting information on demonstrable progress pursuant to decision 22/CP.7;

5. Requests the secretariat, under the guidance of the SBSTA in collaboration with relevant international and intergovernmental organizations of Annex I and non-Annex I Parties active in the area of policies and measures, to support this work by organizing, inter alia, workshops and side events and invites such organizations to provide input as appropriate and to present a status report on their activities related to policies and measures to the SBSTA at its seventeenth session;

6. Requests the secretariat to make available the information on policies and measures implemented and planned related to this work as well as to provide information on policies and measures reported in the third national communications by Annex I Parties when available;

7. Requests the SBSTA to consider at its seventeenth session the initial results obtained from the actions taken pursuant to this decision and to report them to the Conference of the Parties at its eighth session with a view to considering any further action; 
FCCC/CP/2001/13/Add.1

English

Page 67

8. Invites Annex I Parties and interested international organizations to provide the necessary financial support for the workshops and other activities identified in this decision.

$8^{\text {th }}$ plenary meeting 10 November 2001 


\title{
Decision 14/CP.7
}

\section{Impact of single projects on emissions in the commitment period}

\author{
The Conference of the Parties,
}

Recalling its decision 1/CP.3, paragraph 5 (d),

Recalling further its decision 5/CP.6, containing the Bonn Agreements on the implementation of the Buenos Aires Plan of Action,

Having considered the conclusions of the Subsidiary Body for Scientific and Technological Advice at its resumed thirteenth session, ${ }^{1}$ Convention,

Recognizing the importance of renewable energy in meeting the objective of the

1. Decides that, for the purpose of this decision, a single project is defined as an industrial process facility at a single site that has come into operation since 1990 or an expansion of an industrial process facility at a single site in operation in 1990;

2. Decides that, for the first commitment period, industrial process carbon dioxide emissions from a single project which adds in any one year of that period more than 5 per cent to the total carbon dioxide emissions in 1990 of a Party listed in Annex B to the Protocol shall be reported separately and shall not be included in national totals to the extent that it would cause the Party to exceed its assigned amount, provided that:

(a) The total carbon dioxide emissions of the Party were less than 0.05 per cent of the total carbon dioxide emissions of Annex I Parties in 1990 calculated in accordance with the table contained in the annex to document FCCC/CP/1997/7/Add.1;

(b) Renewable energy is used, resulting in a reduction in greenhouse gas emissions per unit of production;

(c) Best environmental practice is followed and best available technology is used to minimize process emissions;

3. Decides that the total industrial process carbon dioxide emissions reported separately by a Party in accordance with paragraph 2 above shall not exceed 1.6 million tonnes of carbon dioxide annually on the average during the first commitment period and cannot be transferred by that Party or acquired by another Party under Articles 6 and 17 of the Kyoto Protocol;

\footnotetext{
FCCC/SBSTA/2000/14
} 
4. Requests any Party that intends to avail itself of the provisions of this decision to notify the Conference of the Parties, prior to its eighth session, of its intention;

5. Requests any Party with projects which meet the requirements specified above, to report emission factors, total process emissions from these projects, and an estimate of the emission savings resulting from the use of renewable energy in these projects in their annual inventory submissions;

6. Requests the secretariat to compile the information submitted by Parties in accordance with paragraph 5 above, to provide comparisons with relevant emission factors reported by other Parties, and to report this information to the Conference of the Parties serving as the meeting of the Parties to the Kyoto Protocol. 